\title{
Working
}

Paper 


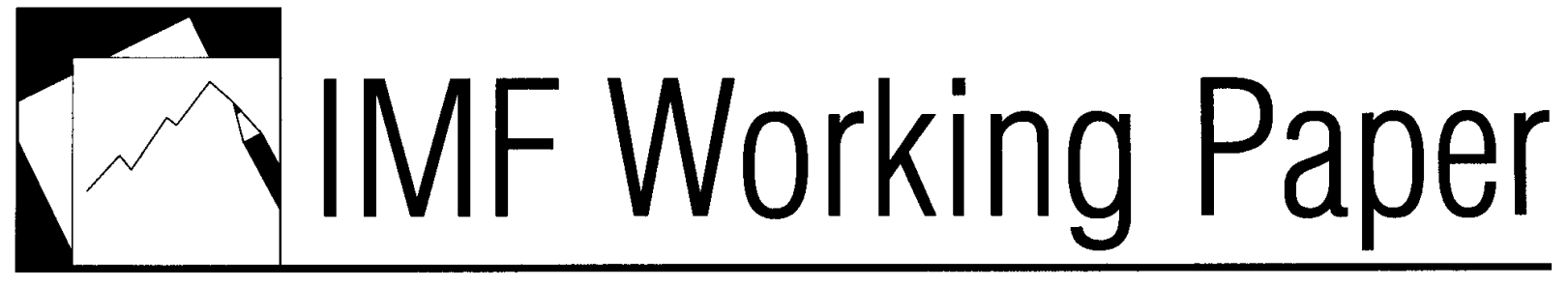

\title{
Quarterly GDP Revisions in G-20 Countries:
} Evidence from the 2008 Financial Crisis

\author{
Manik Shrestha and Marco Marini
}




\title{
IMF Working Paper
}

Statistics Department

\section{Quarterly GDP Revisions in G-20 Countries: Evidence from the 2008 Financial Crisis}

\section{Prepared by Manik Shrestha and Marco Marini ${ }^{1}$}

Authorized for distribution by Kimberly D. Zieschang

March 2013

\section{This Working Paper should not be reported as representing the views of the IMF.}

The views expressed in this Working Paper are those of the author(s) and do not necessarily represent those of the IMF or IMF policy. Working Papers describe research in progress by the author(s) and are published to elicit comments and to further debate.

\begin{abstract}
This paper presents a statistical analysis of revisions in quarterly gross domestic product (GDP) of the Group of Twenty countries (G-20) since 2000. The main objective is to assess whether the reliability of early estimates of quarterly GDP has been weakened from the turmoil of the 2008 financial crisis. The results indicate that larger and more downward revisions were observed during the years 2008 and 2009 than in previous years.

JEL Classification Numbers: C82, E32.

Keywords: Gross Domestic Product, Quarterly National Accounts, Revisions Analysis. Author's E-Mail Address: mshrestha@imf.org, mmarini@imf.org.

\footnotetext{
${ }^{1}$ We would like to thank our colleagues Alfredo Leone, Robert Heath, Kim Zieschang, Ethan Weisman, Antonio Galicia-Escotto, Yuko Hashimoto, and Nolvia Saca Saca for their helpful comments to improve an earlier draft of this paper. We would also like to thank Rosemary Fielden for providing assistance with this research.
} 


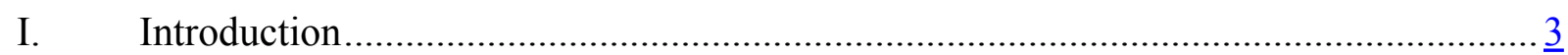

II. Revisions in Quarterly GDP Estimates: Are They Influenced by the Business Cycle? . $\underline{4}$

III. GDP Revisions from 2008 Onward: A Comparison with the Previous Years .............. 1

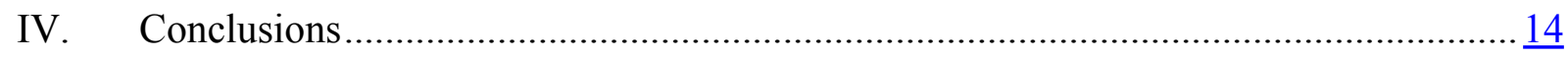

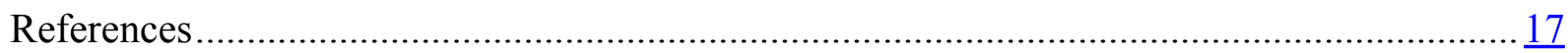

\section{Appendixes}

I. Revisions Analysis of GDP: Summary Tables and Charts.......................................... 19

II. Revisions Analysis of GDP: Country Tables and Charts............................................. 25

III. Statistical Analysis of Revisions................................................................................. 41 


\section{INTRODUCTION}

This paper attempts to assess the extent to which the reliability of early estimates of quarterly gross domestic product (GDP) of the Group of Twenty countries (G-20) has been influenced by the 2008 financial crisis. The reliability of an economic indicator is usually assessed by looking at its revisions over time. To achieve our objective, we present a descriptive analysis of the revisions of the quarterly GDP growth rates in 16 G-20 countries since 2000 . We calculate summary statistics of the quarterly GDP revisions during the years 2008-2011, and compare them with the same statistics calculated over the previous years to identify similarities and differences in the revisions history for each country.

The motivation behind this work derives from the perception that the early estimates of quarterly GDP, and the short-term statistics these estimates are based on, become less reliable during times of strong economic changes. Compilation systems of quarterly GDP in most advanced countries are well designed to keep up with an economy on a steady path of growth, but are less suitable to detect sudden changes of direction in real-time. A number of revision studies have confirmed that the size and direction of data revisions change with the state of the business cycle (see Croushore, 2011 and references therein). For instance, one common result is that, for variables measuring economic activity, downward revisions tend to appear during recessions and upward revisions during expansions.

This worldwide analysis on GDP revisions since 2000 was made possible thanks to the availability of the Organization for Economic Co-operation and Development (OECD)'s Main Economic Indicators (MEI) Original Release Data and Revisions Database ${ }^{2}$ (see Di Fonzo, 2005; McKenzie, 2006). This database contains time series of 21 key economic variables for the OECD member (and a few nonmember) countries as they were historically published in each monthly edition of the OECD MEI publication. In addition, we used automated spreadsheet programs available from the OECD MEI website to create the revision triangles ${ }^{3}$ for each country and conduct our exercise. From the numerous research studies on data revisions that made use of it (for example McKenzie, 2006; McKenzie and Adam, 2007; Tosetto, 2009), ${ }^{4}$ the OECD real-time database has shown to successfully serve its purposes and to provide a valuable and continuing service to both producers and users of official statistics.

\footnotetext{
${ }^{2}$ http://stats.oecd.org/mei

${ }^{3}$ The name "triangle" derives from the typical shape of the table formed by arranging (column-wise or rowwise) the sequence of historically published time series for the same variable.

${ }^{4}$ Comparisons of GDP revisions for different countries have been also conducted by the European Central Bank (Branchi et al, 2007 and Dieden and Olsson, 2008).
} 
It is not the intention of this paper to evaluate and compare the quality of GDP data or the strength of the national accounts compilation systems of the countries considered. Many factors may have influenced the revision process in each country, including the introduction of major, or benchmark, revisions of national accounts which are supposed to increase the quality of the estimates. In addition, it is important to note that absence of revisions is not necessarily an indication of good quality. In fact, in certain cases where data are not revised to take into account better data or changing economic situations, the absence of revisions indicate poor data quality.

Our comparisons (and comments) focus on identifying patterns between the GDP revisions of quarters published in the years from 2000 to 2007 and the GDP revisions of quarters published from 2008 to 2011 for each individual country. We will make use of summary charts and tables with statistics for all the countries considered, in order to provide the reader with an immediate picture of the revision process during these years. It is also important to note that we analyze only the revisions of the quarterly aggregate GDP growth rates. Identification of factors responsible for revisions will require analysis at more detailed levels, which compilers in each country should be able to conduct.

As we will see, for G-20 countries considered in our exercise, our revisions analysis shows that during the years 2008 and 2009 (i) revisions to early estimates of quarterly GDP growth rates were of greater magnitude than in previous years, and that (ii) downward revisions were more frequent and intense than in the previous years. We note, however, that for some G-20 countries the size of revisions was similar or even smaller than in the past.

The paper is structured as follows. Section II explains why revisions to GDP estimates play a fundamental role in the national accounts compilation to incorporate better data sources and improve methodology and why they may differ during business cycle phases. Section III presents the revisions analysis on the quarterly GDP for 16 G-20 countries. Section IV provides some concluding remarks and highlights areas for further research. Tables and charts with statistics on revisions are presented in the appendices.

\section{ReVisions In QuARTERLy GDP Estimates: ARE TheY INFLUENCED BY THE BUSINESS CYCLE?}

To meet the needs of decision makers and economic analysts, quarterly GDP estimates are required to be both accurate and timely. ${ }^{5}$ Data sources used in the GDP compilation process, however, are available only some time after the end of the quarter (months, or years if we take into account annual surveys or administrative data). As a consequence, more timely

\footnotetext{
${ }^{5}$ Accuracy refers to the closeness between the estimated value and the (unknown) true value; timeliness refers to the length of time between the end of the reference period and the time of publication.
} 
GDP estimates are generally less accurate because their calculation is based on a partial set of information. Statistical agencies usually tackle this trade-off between timeliness and accuracy by publishing an early estimate of GDP within a few weeks after the end of the quarter and then releasing subsequent, more accurate, GDP estimates that incorporate additional and better source data available after the first publication.

Inevitably, early estimates of quarterly GDP are subject to a number of revisions over an extended period of time. There are several reasons for revisions: to incorporate more complete or more comprehensive data sources used in the national accounts compilation; to capture routine calculations (e.g., from benchmarking or seasonal adjustment); to reflect improved methodology or new standards; and to correct errors (see Carlson et al., 2004). Each subsequent estimate incorporates more information than the previous ones and, therefore, is of better quality. Revisions are therefore a necessary step in the national accounts compilation process to improve accuracy of the earlier estimates of GDP.

It follows that an early estimate of quarterly GDP is also required to be reliable. Reliability refers to the closeness of preliminary estimated values to subsequent estimated values. ${ }^{6}$ The concept of reliability, therefore, is strictly related to revisions. An early estimate that undergoes very large and systematic changes over time (i.e., revisions) is deemed to be unreliable, increasing uncertainty and augmenting noise in the decision process of economic agents. Furthermore, it may impair the credibility of the statistical agency.

It is often claimed that revisions to macroeconomic statistics depend on the state of the economy (Croushore, 2011; Sinclair and Stekler, 2011). When an economy is decelerating, for example, the initial release of GDP tends to be higher than later estimates. Consequently, downward revisions are more expected during recessions. The opposite holds true in times of strong economic growth, when upward revisions are undertaken to the first available estimate. Studies have also shown an increase in the volatility of revisions during recessions, suggesting that early data are less reliable in tougher economic times (Swanson and van Dijk, 2006).

Besides the empirical evidence in the subject literature, it is reasonable to assume that the different phases of the business cycle may determine asymmetries in the quarterly GDP revision process. These asymmetries are likely to arise if we look at the way in which the quarterly compilation systems of GDP are designed in many countries. Quarterly GDP is calculated from a number of available short-term indicators for the quarter integrated with assumptions (e.g., fixed input-output ratios) on the quarterly movements of unobserved

\footnotetext{
${ }^{6}$ It is important to note that reliability is a distinct aspect of quality from accuracy: for instance, data that are not revised are not necessarily the most accurate.
} 
variables. In addition, in the calculation of early estimates compilers make more recourse to forecasting techniques to fill in information available with more delay. ${ }^{7}$

Two main factors (one associated with data on current activities and another with statistics techniques) can help justify a different pattern in GDP revisions during expansionary and recessionary economic phases. First, the short-term indicators used in quarterly compilation are derived from a sample of businesses that may lose its representativeness when the economy is experiencing rapid and unpredicted changes. Surveys conducted at the monthly frequency generally collect data from large and medium enterprises: on the contrary, smallsize and unincorporated enterprises are often out of scope or, when observed, characterized by higher nonresponse rates. In addition, the methodology used to impute incomplete responses and nonresponses (data supplied in the previous period, or data provided by similar businesses) may offer a conservative view on the state of the economy. These factors increase survey errors and may lead to distortions in the measurement of growth.

Second, the methodology used to calculate the quarterly GDP is thoroughly formulated on the assumption of a "linear" behavior of the economy in the short term. Fixed-ratio assumptions, benchmarking of subannual data to annual data, seasonal adjustment procedures, and estimation of missing indicators are all statistical techniques commonly used in the quarterly compilation which tend to extrapolate the current developments from the most recent observations along a predictable path. Any deviations of the economy from this path cause a departure from the basic assumption, and inevitably introduce more uncertainty in the quarterly data.

Determining how these factors may influence quarterly GDP revisions during expansionary and recessionary phases, and take appropriate actions to prevent them, is not an easy task for compilers. Real-time information on nonresponse rates of surveys are generally not disseminated, therefore it is difficult for compilers of national accounts to identify (and properly adjust the preliminary data for) a different nonresponse behavior during expansion or recession times. In addition, the quarterly compilation methodology uses several assumptions on quarterly patterns, many derived from the annual accounts, and it really is hard to determine in real-time whether these assumptions are violated in the middle of rapid changes of directions in the economy.

In sum, there are many a priori reasons to assume that quarterly GDP revisions are influenced by business cycle movements. Unfortunately, it is very difficult to prove and generalize this belief through empirical analysis. Real-time data to conduct revisions analysis on quarterly

\footnotetext{
${ }^{7}$ This is often referred to as "nowcasting" in the quarterly GDP compilation context, since forecasting methods are used to provide estimates of slowly arriving data up to the reference period of the current release, but not for future periods. For the latter exercise, the usual term "forecasting" is deemed more appropriate.
} 
GDP have been made available only recently, and the sample of observations covers a few complete cycles of the economy. The scope of this work is then limited to analyzing the impact of one particular event on GDP revisions. We explore the revisions of the published quarterly GDP growth rates of G-20 countries since 2000, and take advantage of the 2008 financial crisis and its aftermath, to verify whether quarterly GDP revisions have been significantly different during this period.

\section{GDP REVISIONS FROM 2008 ONWARD: A COMPARISON WITH THE PREVIOUS YEARS}

\section{Dataset}

The analysis in this paper considers quarterly GDP estimates of 16 G-20 countries published from June 2000 to April 2012. Data are extracted from the OECD MEI Real-Time and Revisions Database, ${ }^{8}$ which provides access to time series data for 21 key economic variables as originally published in each monthly edition of the MEI publication from February 1999 onward. Data are available for all OECD countries, the Euro area, China, India, Brazil, South Africa and the Russian Federation. The variable selected is "GDP, Total Constant prices."

The 16 G-20 countries considered are Australia, Brazil, Canada, France, Germany, India, Indonesia, Italy, Japan, Korea, Mexico, Russian Federation, South Africa, Turkey, the United Kingdom (U.K.) and the United States of America (U.S.A.). The three remaining G-20 countries, Argentina, China, and Saudi Arabia, are not considered in this analysis because quarterly GDP data are not available in the OECD real-time database. ${ }^{9}$

Data availability varies across countries. Table I.1 shows the quarters available for each country. The full span of quarters is available for a group of 11 countries (Australia, Canada, France, Germany, Italy, Japan, Korea, Mexico, Turkey, U.K., U.S.A.), with 32 quarters before 2008 (from 2000:Q1 to 2007:Q4) and 15 quarters after 2008 (from 2008:Q1 to 2011:Q3). For the group of the remaining five countries (Brazil, India, Indonesia, Russian Federation, and South Africa) we consider shorter spans of quarterly GDP releases than the 11 countries above mentioned (see Table I.1 for details). Therefore, revisions statistics for these five countries will be calculated on a reduced number of quarters. ${ }^{10}$ Naturally, the different sample of observations considered must be taken into account when comparing revision statistics between the two groups of countries.

\footnotetext{
${ }^{8}$ http://stats.oecd.org/mei/default.asp?rev=1

${ }^{9}$ Since 2011, China has started the publication of quarterly seasonally adjusted growth rates of GDP in discrete form (quarterly cumulated data were previously available). Saudi Arabia does not disseminate quarterly GDP data.

${ }^{10}$ India and Indonesia have the shortest sample of observations (22 and 23 quarters).
} 
GDP data are expressed in seasonally adjusted (SA) form in the MEI, with the exception of some early estimates that are reported unadjusted for some countries (mostly before 2008). As regards the volume evaluation, GDP data are either expressed in chain-linked form (in monetary or index terms) or at the constant prices of a base year. For many countries the GDP volume evaluation has been changed over the period considered, thanks to the regular revision process (change of the base year) or to major improvements in the national accounts compilation process (i.e., introduction of chain-linking). As noted, we do not control for these methodological changes in our analysis.

GDP revisions are analyzed with regard to both quarter-to-quarter (or $q / q-1$ ) rates of change (each quarter compared with the previous one) and year-on-year (or $q / q-4$ ) rates of change (each quarter compared with the corresponding quarter of the previous year). We will give more emphasis to the latter evaluation in this study. First, some early vintages are available only in unadjusted form for some countries (as noted). Second, countries adopt different seasonal adjustment procedures and policies which may influence more $q / q-1$ rates than annual rates. Therefore, we believe that revisions to $q / q-4$ changes are more comparable than revisions to $q / q-1$ changes in both the temporal and country dimensions. Hereafter, unless otherwise specified, with quarterly GDP growth we refer to $q / q-4$ growth rates.

For the purposes of this work, we choose to measure three types of revisions to the first estimate of quarterly GDP:

- $\quad$ the first quarterly revision, that is made three months after the first GDP release to incorporate more complete, or better reported, quarterly source data (generally within three months after the end of the quarter). For instance, for countries having one GDP publication every three months with a 60-day timeliness, the first quarterly revision for a given quarter is measured as the difference between the second estimate released after 150 days and the first estimate released after 60 days;

- the first annual revision, that is made after one year when preliminary information from annual surveys and administrative data are incorporated in the quarterly GDP compilation process and the quarterly GDP are benchmarked to the first annual GDP; and

- $\quad$ the second annual revision, that is made after two years when more consolidated (sometimes final) information from annual sources are made available. By this time, almost all regular sub-annual and annual data sources are incorporated into the annual and quarterly GDP data. 


\section{Revisions analysis}

We consider four estimates of quarterly GDP growth for each quarter: the first estimate (1st), the estimate released three months after the end of the quarter $(3 \mathrm{~m})$, the estimate released after one year $(1 y)$, and the estimate released after two years $(2 y)$. Let us denote with $y^{1 s t}, y^{3 m}, y^{1 y}$, and $y^{2 y}$ the four estimates (or vintages), respectively, for a generic quarter $t$. Four types of revisions are calculated:

$$
\begin{aligned}
& r_{t}^{1}=y_{t}^{3 m}-y_{t}^{1 s t} \\
& r_{t}^{2}=y_{t}^{1 y}-y_{t}^{3 m} \\
& r_{t}^{3}=y_{t}^{2 y}-y_{t}^{1 y} \\
& r_{t}^{4}=y_{t}^{2 y}-y_{t}^{1 s t}
\end{aligned}
$$

where

$$
y_{t}^{i}=\left(\frac{G D P_{t}^{i}}{G D P_{t-4}^{i}}-1\right) \cdot 100
$$

and the index $i$ indicating the four vintages. Table I.2 in Appendix I uses a timeline chart to identify the four GDP estimates and the types of revisions considered using the example of quarter 2009:Q1 and assuming a first estimate published after 30 days.

Each vintage incorporates information with different maturity. The first available vintage, $y^{1 s t}$, is published within the next quarter (usually between 25 and 80 days) and therefore is based on a limited number of short-term indicators available at the time of publication. Three months after the first estimate, a more comprehensive set of monthly/quarterly indicators is available. The first stage of revision, $r_{t}^{1}$, catches this augmented set of information available at the quarterly level. One year after the first estimate, benchmarks from the annual accounts (based on provisional results from annual surveys and administrative sources) are incorporated in the quarterly estimates. The second revision considered, $r_{t}^{2}$, namely the difference between the one-year estimate $y^{1 y}$ and the three-month estimate $y^{3 m}$, detects this more accurate information coming from provisional annual information. Our revision process ends with the two-year vintage $y^{2 y}$ (namely, the estimate available two years after the first estimate), which generally relies upon the full set of information from annual and quarterly sources. In this work we consider the two-year estimate as the final estimate. ${ }^{11}$ The two-year

\footnotetext{
${ }^{11}$ Actually, the revision process of quarterly GDP data is usually longer than two years due to many different changes that can be introduced in the national accounts compilation. The aim of this work, however, is to analyze the first stages of the revision process, which are mostly driven by the additional data sources made available after the first release. Therefore, the GDP estimate published after two years can be considered a good term of comparison for the first estimate.
} 
estimate is first compared with the one-year estimate, with $r_{t}^{3}$ highlighting the improvements from the more consolidated annual sources available over the provisional ones; and then with the first estimate $y^{1 s t}$ to measure the whole revision process. Revision $r_{t}^{4}$ is a summary of the different stages of revision $r_{t}^{1}, r_{t}^{2}$, and $r_{t}^{3}$.

We assess whether there was a change in the size and direction of revisions to GDP growth from 2008 onward, the year when the global financial crisis began. To identify this effect, we group the quarters available in two sub-samples: the pre-2008 period, from the beginning quarter available for each country to 2007:Q4, and the post-2008 period, the quarters from 2008:Q1 to 2011:Q3. We calculate for each of these quarters the four types of revisions previously indicated and calculate revisions statistics ${ }^{12}$ over both the pre-2008 period and the post-2008 period.

Figure I. 1 shows the 16 G-20 countries sorted by average annual growth rates in the pre-2008 period (dark blue bars). Light blue bars indicate the post-2008 period, with the average growth reported along the $X$-axis. ${ }^{13} \mathrm{We}$ draw from this chart that, Indonesia apart, all countries experienced a marked deceleration in GDP growth after 2008, which turned out to be below 1 percent in four countries (France, U.S.A., Germany and Canada) and negative in three countries (Italy, Japan, and the U.K.).

\section{Results}

Figure I.2 compares the mean absolute revision $(M A R)$ to the first estimate of quarterly GDP growth $\left(y^{1 s t}\right)$ from the estimate published two years later $\left(y^{2 y}\right)$ calculated in the pre-2008 period and the post-2008 period. As explained in Appendix III, the MAR is a measure of the size of revisions irrespective of the sign. For the seven countries in the top-panel, the MAR value is smaller in the post- 2008 period. The reduction is particularly evident for Japan ( 0.68 percent vs. 1 percent), South Africa ( 0.38 percent vs. 0.84 percent) and Turkey ( 0.44 percent vs. 0.81 percent). The remaining nine countries show an increase in the size of revisions, with the U.S.A. (1.13 percent vs. 0.53 percent), the U.K. (0.95 percent vs. 0.24 percent), and Italy ( 0.45 percent vs. 0.16 percent) presenting the largest differences.

\footnotetext{
${ }^{12}$ The revisions statistics used are illustrated in Appendix III. In this section we simplify the notation and drop the superscript indicating the terms of comparison. Unless otherwise noted, the later estimate $L$ is the two-year estimate $y^{2 y}$ and the earlier estimate $E$ is the first estimate $y^{1 s t}$.

${ }^{13}$ All charts of this paper will use dark blue to indicate the pre-2008 period and light blue for the post-2008 period.
} 
The $M A R$ values are reported in the scatter plot of Figure I.3. The values calculated over the pre-2008 period are along the $X$-axis, while those calculated over the post-2008 period are along the $Y$-axis. Countries that are close to the main diagonal have revisions of similar intensity in the two periods. As already noticed, the U.S.A. and the U.K. show the largest differences in quarterly GDP revisions after 2008 compared with the revisions before 2008.

To appreciate the direction of revisions, the mean revision $(M R)$ indicator is plotted in Figure I.4. A positive (negative) $M R$ value signals that, on average, the first estimate of quarterly GDP growth is lower (higher) than the two-year estimate. Countries are sorted out according to their $M R$ values during the post-2008 period (positive $M R$ values on top, negative $M R$ values on bottom). Half of the countries show a positive $M R$, but the other eight countries have a negative $M R$ (U.S.A., India, Japan, France, Italy, Canada, Brazil, and Germany). This is in contrast with the pre-2008 period when negative $M R$ values are noted only for four countries, the U.S.A, Japan, Mexico, and Italy (-0.51 percent, -0.13 percent, -0.02 percent, and -0.01 percent, respectively). This implies that more countries overestimated GDP growth in their first release in the post-2008 period than in the pre-2008 period. The largest negative $M R$ values in the post-2008 period are noted for the U.S.A. ( -1.13 percent), India ( -0.71 percent), Japan ( -0.63 percent), France $(-0.57$ percent), and Italy $(-0.43$ percent).

The $M R$ statistic can disguise larger absolute revisions: as noted above nine countries show an increase in the size of revisions. For the U.K. it is interesting to note that, although the mean revision to GDP growth is very close to zero (0.02 percent, compared with 0.04 percent before 2008), the U.K. has the second largest MAR value after 2008 ( 0.95 percent). This implies that for the U.K., on average, larger positive and negative revisions offset each other after 2008.

A more detailed analysis of the quarterly GDP revisions for each of the 16 countries is presented in Appendix II. First, a table showing the revisions statistics on quarterly GDP growth rates ( $q / q-4$ rates of change) calculated over the pre-2008 period and over the post2008 period is presented. The table reports, in order, the mean absolute revision $(M A R)$, the mean revision $(M R)$, the relative $M A R$, the standard deviation of revisions, the minimum revision, the maximum revision, and the range (max revision - min revision) ${ }^{14}$ The statistics are shown for the four stages of revision investigated. Second, two bar charts are shown to visualize and compare the $M A R$ (left panel) and the $M R$ (right panel) values in the two periods at different horizons of revisions. Finally, the bottom chart shows the four series of quarterly GDP growth rates by time of publication. For example, the blue line shows the

\footnotetext{
${ }^{14}$ See Appendix III for a description of these statistics.
} 
series of the first estimates and the red line shows the series of estimates published two years later. $^{15}$

It is interesting to single out how the quarterly GDP revision process has evolved in the U.K. and the U.S.A., the two countries that experienced the largest quarterly GDP revisions after 2008. The MAR values reported in Figures II.15a and II.16a show that most of the revisions have been introduced at the time of the two-year estimate, when compilers generally have access to more comprehensive data from annual surveys on businesses and consumers. In contrast, the MAR calculated on the first two revision stages $\left(r_{t}^{1}\right.$ and $\left.r_{t}^{2}\right)$ are only slightly higher in the post-2008 period.

Looking at the $M R$ indicator (right panel), the two countries show completely different patterns of revisions. The average revision after two years to the U.K.'s quarterly GDP first estimate is very close to zero in the two periods ( 0.04 percent and 0.02 percent), but in the post-2008 period we can see that a negative (average) revision ( -0.09 percent) after three months is offset by a positive (average) revision ( 0.15 percent) after one year. On the contrary, the $M R$ values for the U.S.A.'s quarterly GDP at the four intervals are all negative after 2008 ( -0.12 percent, -0.13 percent, -0.66 percent, and -1.13 percent). This result signals a systematic overestimation of the final quarterly GDP growth in the first available estimate. A similar pattern, although with minor intensity, is also found for the quarters before 2008 (with the exception of the first stage of revision $r_{t}^{1}$, for which the $M R$ is slightly positive).

It is now worth looking at the sequence of estimates for the quarters in the 2008 and 2009 years, namely the years where the effects of the financial crisis were more intense. Figures I.5-8 show the quarterly GDP growth for these eight quarters in four countries (the four quarters of 2008 in the left panel, the four quarters of 2009 in the right panel): the U.S.A. and the U.K., which shows significantly higher revisions (in absolute terms) after 2008, and Canada and Germany, which on the contrary features a similar GDP revision pattern in the two periods. We can appreciate how earlier estimates of quarter 2008:Q4, epicenter of the crisis, have been revised downward in both the U.S.A. and the U.K. While this pattern has continued for all the quarters in 2009 in the U.S.A., the U.K. has made large upward revisions to GDP growth for quarters 2009:Q3 and 2009:Q4 (note that these revisions offset the downward revisions in 2008 and lead to a $M R$ value close to zero, as noted earlier). For Canada and Germany, two other advanced countries which experienced a marked deceleration of GDP after the 2008 crisis (see Figure I.1), the sequence of estimates of quarterly GDP growth looks more stable but still the first estimate tends to be higher than

\footnotetext{
${ }^{15}$ The same tables and charts are available for $q / q-1$ rates of change, but are not shown in this paper for the sake of brevity. They are available upon request from the authors.
} 
the two-year estimate (the $M R$ values are in fact -0.17 percent and -0.06 percent, respectively).

Further, we verify if the first estimate of quarterly GDP correctly indicates the direction of change and if it correctly detects acceleration and deceleration. A similar analysis was presented by a revisions study of the European Central Bank (ECB) for Euro area countries (ECB, 2009). We move our attention to the $q / q-1$ growth rate, which is a more appropriate measure to analyze short-term movements in the economy. Only eight countries are considered in this analysis, ${ }^{16}$ those for which we have official seasonally adjusted GDP series published since 2000 . This ensures better comparability of quarterly seasonally adjusted movements from different releases.

Two different vintages of the quarterly GDP estimates for the same quarter, denoted with $a$ and $b$, have the same direction of change when their $q / q-1$ change have the same sign, that is when either condition

$$
\Delta G D P_{t}^{a}>0 \wedge \Delta G D P_{t}^{b}>0 \quad \text { (positive growth in both cases) }
$$

or condition

$$
\Delta G D P_{t}^{a}<0 \wedge \Delta G D P_{t}^{b}<0 \quad \text { (negative growth in both cases) }
$$

is satisfied, where $\Delta$ is the operator calculating the first differences of a series.

The same two different vintages of the quarterly GDP estimates indicate acceleration or deceleration when one of the following conditions applies:

$$
\begin{gathered}
\Delta \Delta G D P_{t}^{a}>0 \wedge \Delta \Delta G D P_{t}^{b}>0 \text { (both acceleration); or } \\
\Delta \Delta G D P_{t}^{a}<0 \wedge \Delta \Delta G D P_{t}^{b}<0 . \text { (both deceleration) }
\end{gathered}
$$

Table I.3 shows the percentage of times the first quarterly GDP estimate correctly indicates the direction of growth published three months later, one year later, and two years later. Table I.4 reports the percentage of times the first quarterly GDP estimate correctly indicates acceleration or deceleration compared with the subsequent estimates. The first three columns refer to the period 2000:Q1-2007:Q4, while the last three columns refer to the period 2008:Q1-2011:Q3 for the comparison 3m-1st, to the period 2008:Q1-2010:Q4 for the comparison 1y-1st, and to the period 2008:Q1-2009:Q4 for the comparison 2y-1st.

\footnotetext{
${ }^{16}$ Australia, Canada, France, Germany, Italy, Japan, U.K., and U.S.A.
} 
Looking at the comparison with the two-year estimate, the direction of quarterly GDP change for all the post-2008 quarters is correctly identified by the first estimate in three countries (Australia, Germany, and Italy), while one change of direction occurred in four countries (from positive to negative for Canada, France, Japan, and U.S.A.) and two changes of direction are noticed in the U.K. (from positive to negative in 2008:Q2 and from negative to positive in 2009:Q3). Same acceleration or deceleration of quarterly GDP after 2008 is correctly estimated in four countries (France, Germany, Japan, and the U.K.), with one change in Italy and the U.S.A. (both from acceleration to deceleration in 2009:Q3), two changes in Canada (from deceleration to acceleration in 2009:Q2 and 2009:Q3) and five changes in Australia (both directions). ${ }^{17}$

\section{Conclusions}

In this paper we have examined the quarterly GDP revisions in $16 \mathrm{G}-20$ countries during the period 2000-2011. Our objective was to evaluate whether the reliability of early estimates of GDP have been undermined during the years 2008 and 2009, a period when G-20 economies experienced strong economic changes associated with the 2008 global financial crisis. We would like to emphasize that this paper is limited to evaluating factual patterns of quarterly GDP revisions in G-20 countries for understanding how robust are the early (first) quarterly GDP releases in situations of strong economic changes.

Our results indicate:

- First, for around half of the G-20 countries revisions to the first estimates of quarterly GDP by the second annual revision are of greater magnitude for the quarters of the years 2008-2009 compared with the quarters of the previous years. The largest revisions (in terms of mean absolute revision statistic) are shown for the U.K. and the U.S.A., where the 2008 financial crisis originated and spread from the financial sector to the real sector and to other economies. Nevertheless, for some G-20 countries revisions after 2008 are lower despite the marked deceleration these economies experienced in that period (most notably, South Africa and Turkey).

- $\quad$ The second finding is that overestimations in the first release of quarterly GDP have been more frequent for the 2008-2009 quarters compared with the quarters of the

\footnotetext{
${ }^{17}$ Sometimes rates of change, or acceleration/deceleration rates, are very close to zero. A change of direction or a change from acceleration to deceleration (or vice versa) may occur even in case of small revisions. This is the case of Australia, for example, where the first estimate for 2008:Q3 (-0.3\%) and 2009:Q4 (+0.6\%) have been revised to a very small acceleration $(+0.03 \%)$ and a very small deceleration $(-0.04 \%)$, respectively, with the publication of the two-year estimate. Furthermore, it has been noted that Australia has introduced the System of National Accounts 2008 in September 2009, therefore the GDP revisions for the most recent quarters may be affected from the update of concepts, definitions, sources of data and methods.
} 
previous years. Negative $M R$ values are found for eight countries in the post-2008 period, compared with only four countries in the pre-2008 period. More negative values of the $M R$ statistics after 2008 are noted for countries with a significant fall in the GDP during the years 2008-2009 (in particular U.S.A., and Japan), while for the U.K. the mean revision to the first estimate of quarterly GDP growth after two years is confirmed to be around zero despite the strong economic downturn (although it experienced more volatile fluctuations in revisions with large negative and positive revisions to the 2008-2009 quarters).

The results shown in this study are in line with the empirical evidence in a number of revision studies that have shown increased uncertainty of the earlier estimates of quarterly GDP in tougher economic times. However, we do not intend to generalize our findings beyond our particular study or sample. Several factors that are left unaccounted for in this study may have led to larger or smaller revisions during the period analyzed. We would also like to caution that it would not be appropriate to make judgments on the quality of the GDP compilation systems solely from an analysis of revisions.

Despite this work offering a detailed assessment of the recent quarterly GDP revision patterns for G-20 countries, it has not investigated the underlying causes that may have generated those revisions. In this respect, future research may expand our analysis in two directions. First, quarterly GDP is generally calculated as the aggregation of (more or less) detailed production, expenditure, and income components (or a combination of them). Consequently, quarterly GDP revisions can be seen as made up of quarterly revisions of these underlying components. A detailed analysis by GDP components may be helpful to signal which variables of the accounts are responsible for the largest shares of revisions. That kind of analysis would require running the same revision analysis undertaken in this work for the GDP components. Real-time data for GDP components (mostly from the expenditure side) are available in the OECD MEI database.

Second, it would be interesting to determine whether there are certain characteristics in the GDP compilation systems currently adopted by countries that are more likely to generate revisions. For example, one may find that GDP revisions across countries are influenced by a particular type of seasonal adjustment procedure, or by a class of time-series or econometric models used to forecast missing indicators, or even by the use of certain short-term data sources that are more subject to revisions than others. This analysis would require a deep understanding of the quarterly national accounts methodology used by these countries, including data sources, methods and compilation practices, and an appropriate statistical model to put these characteristics in relationship with the GDP revisions.

We believe that compilers of quarterly GDP can learn important lessons from extraordinary events like the 2008 financial crisis. Countries should investigate ways to improve the reliability of quarterly GDP in times of strong economic changes. Our analysis reveals that 
each of the countries considered has a specific quarterly revision pattern, which should be properly understood and addressed in order to improve the reliability of future GDP estimates. For example, countries could consider broadening the spectrum of short-term indicators on which the early estimates of quarterly GDP are based on and improving the statistical techniques used in the quarterly compilation systems (such as the benchmarking and seasonal adjustment procedures) .

Finally, we would like to stress the importance of revisions analysis in monitoring the quality of national accounts estimates. Statistical agencies should consider revisions analysis as an opportunity to investigate and promptly address any shortcomings of the GDP compilation system. Many countries ${ }^{18}$ have long traditions in conducting revisions analyses and disseminating results. It is to be hoped that our study will stimulate more and more countries to undertake a deeper analysis of factors affecting the reliability of their quarterly GDP estimates. This finding applies to both advanced and emerging market economies.

\footnotetext{
${ }^{18}$ For example, the U.K.'s Office for National Statistics regularly disseminates revisions analysis of national accounts data. For example, see Brown et al. (2009) and Murphy (2009).
} 


\section{REFERENCES}

Branchi, M., H. Z. Dieden, W. Haine, C. Horváth, A. Kanutin, and L. Kezber, 2007, "Analysis of Revisions to General Economic Statistics," ECB Occasional Working Paper No. 74 (Frankfurt, Germany).

Brown, G, T. Buccellato, G. Chamberlin, S. Dey-Chowdhury, and R. Youll, 2009, "Understanding the Quality of Early Estimates of Gross Domestic Product," Economic and Labour Market Review, Vol. 3 (12).

Carson, S. C., S. Khawaja, and T.K. Morrison, 2004, "Revisions Policy for Official Statistics: A Matter of Governance," IMF Working Paper 04/87, (Washington, D.C. International Monetary Fund).

Croushore, D., 2011, “Frontiers of Real-Time Data Analysis,” Journal of Economic Literature, 49:1, 72-100.

Dieden, H.Z., and H. Olsson, 2008, "Revisions in Euro Area GDP and Retail Trade data: Reliability, Timeliness and infra-annual Distribution," ECB, contribution to the joint OECD/Eurostat Task Force on "Performing Revisions Analysis for Sub-Annual Economic Statistics."

Di Fonzo, T., 2005, "The OECD Project on Revisions Analysis: First Elements for Discussion,” OECD Short-term Economic Statistics Expert Group, June 2005.

European Central Bank, 2009, “Revisions To GDP Estimates In The Euro Area," Monthly Bulletin, April 2009.

McKenzie, R., 2006, "Undertaking Revisions and Real-Time Data Analysis using the OECD Main Economic Indicators Original Release Data and Revisions Database," OECD Statistics Working Papers, 2006/02, OECD Publishing.

McKenzie, R., Z. Adam, 2007, "Revisions in Quarterly GDP of OECD countries: an Update," paper presented at the Working Party of National Accounts, October 2007.

Murphy, J., 2009, "Revisions to Quarterly GDP Growth and its Components, " Economic and Labour Market Review, vol. 3 (4).

Newey, W. K. and K. D. West, 1987, "A simple, positive semi-definite, heterskedasticity and autocorrelation consistent covariance matrix," Econometrica, 55: 703-708. 
Sinclair, T. M., and H.O Stekler, 2011, "Differences in Early GDP Component Estimates between Recession and Expansions," Research and Program on Forecasting, Working Paper n. 2011-001.

Swanson, N. R. and van Dijk, Dick, 2006, "Are Statistical Reporting Agencies Getting It Right? Data Rationality and Business Cycle Asymmetry," Journal of Business \& Economic Statistics, 24:1, 24-42

Tosetto, E., 2009, “Revisions in Quarterly GDP of OECD countries: an Update," paper presented at the International Seminar on Timeliness, Methodology and Comparability or Rapid Estimates of Economic Trends, May 27-29, 2009, Ottawa, Canada. 


\section{Appendix I. Revisions Analysis of GDP: Summary Tables and Charts}

Table I.1. GDP Quarters Considered in the Revision Analysis (Source: OECD Main Economic Indicators)

\begin{tabular}{|c|c|c|c|c|c|c|}
\hline & \multicolumn{3}{|c|}{ pre-2008 } & \multicolumn{3}{|c|}{ post-2008 } \\
\hline & First quarter & Last quarter & \# quarters* & First quarter & Last quarter & \# quarters* \\
\hline Australia & 2000:Q1 & 2007:Q4 & 32 & 2008:Q1 & 2011:Q3 & 15 \\
\hline Brazil & 2004:Q2 & 2007:Q4 & 15 & 2008:Q1 & 2011:Q3 & 15 \\
\hline Canada & 2000:Q1 & 2007:Q4 & 32 & 2008:Q1 & 2011:Q3 & 15 \\
\hline France & 2000:Q1 & 2007:Q4 & 32 & 2008:Q1 & 2011:Q3 & 15 \\
\hline Germany & 2000:Q1 & 2007:Q4 & 32 & 2008:Q1 & 2011:Q3 & 15 \\
\hline India & 2004:Q4 & 2007:Q4 & 13 & 2008:Q1 & 2010:Q1 & 9 \\
\hline Indonesia & 2006:Q1 & 2007:Q4 & 8 & 2008:Q1 & 2011:Q3 & 15 \\
\hline Italy & 2000:Q1 & 2007:Q4 & 32 & 2008:Q1 & 2011:Q3 & 15 \\
\hline Japan & 2000:Q1 & 2007:Q4 & 32 & 2008:Q1 & 2011:Q3 & 15 \\
\hline Korea & 2000:Q1 & 2007:Q4 & 32 & 2008:Q1 & 2011:Q3 & 15 \\
\hline Mexico & 2000:Q1 & 2007:Q4 & 32 & 2008:Q1 & 2011:Q3 & 15 \\
\hline Russian Federation & 2003:Q1 & 2007:Q4 & 20 & 2008:Q1 & 2011:Q3 & 15 \\
\hline South Africa & 2002:Q1 & 2007:Q4 & 24 & 2008:Q1 & 2011:Q3 & 15 \\
\hline Turkey & 2000:Q1 & 2007:Q4 & 32 & 2008:Q1 & 2011:Q3 & 15 \\
\hline U.K. & 2000:Q1 & 2007:Q4 & 32 & 2008:Q1 & 2011:Q3 & 15 \\
\hline U.S.A. & 2000:Q1 & 2007:Q4 & 32 & 2008:Q1 & 2011:Q3 & 15 \\
\hline
\end{tabular}

${ }^{*}$ maximum number of quarters compared in the sample

Table I.2. GDP Revisions Vintages Considered for Each Quarter: The Case of 2009:Q1

\begin{tabular}{|c|c|c|c|c|c|c|}
\hline Month of publication & $\begin{array}{c}\text { First } \\
\text { estimate }\end{array}$ & $\begin{array}{l}\text { 3-month } \\
\text { estimate }\end{array}$ & $\begin{array}{c}\text { 1-year } \\
\text { estimate }\end{array}$ & $\begin{array}{c}\text { 2-year } \\
\text { estimate }\end{array}$ & & \\
\hline \multicolumn{7}{|l|}{ Apr-09 } \\
\hline May-09 & $1 \mathrm{st}$ & & & & & \\
\hline Jun-09 & & & & & \multirow{2}{*}{$\frac{\vec{n}}{\dot{m}}$} & \multirow{10}{*}{$\frac{\pi}{\frac{\pi}{2}}$} \\
\hline Jul-09 & & & & & & \\
\hline Aug-09 & & $3 m$ & & & & \\
\hline Sep-09 & & & & & \multirow{3}{*}{$\frac{\Xi}{2}$} & \\
\hline$\ldots$ & & & & & & \\
\hline Apr-10 & & & & & & \\
\hline May-10 & & & $1 y$ & & \multirow{4}{*}{$\frac{\vec{T}}{2}$} & \\
\hline Jun-10 & & & & & & \\
\hline$\ldots$ & & & & & & \\
\hline Apr-11 & & & & & & \\
\hline May-11 & & & & $2 y$ & & \\
\hline
\end{tabular}


Figure I.1. Average GDP Growth (percent)

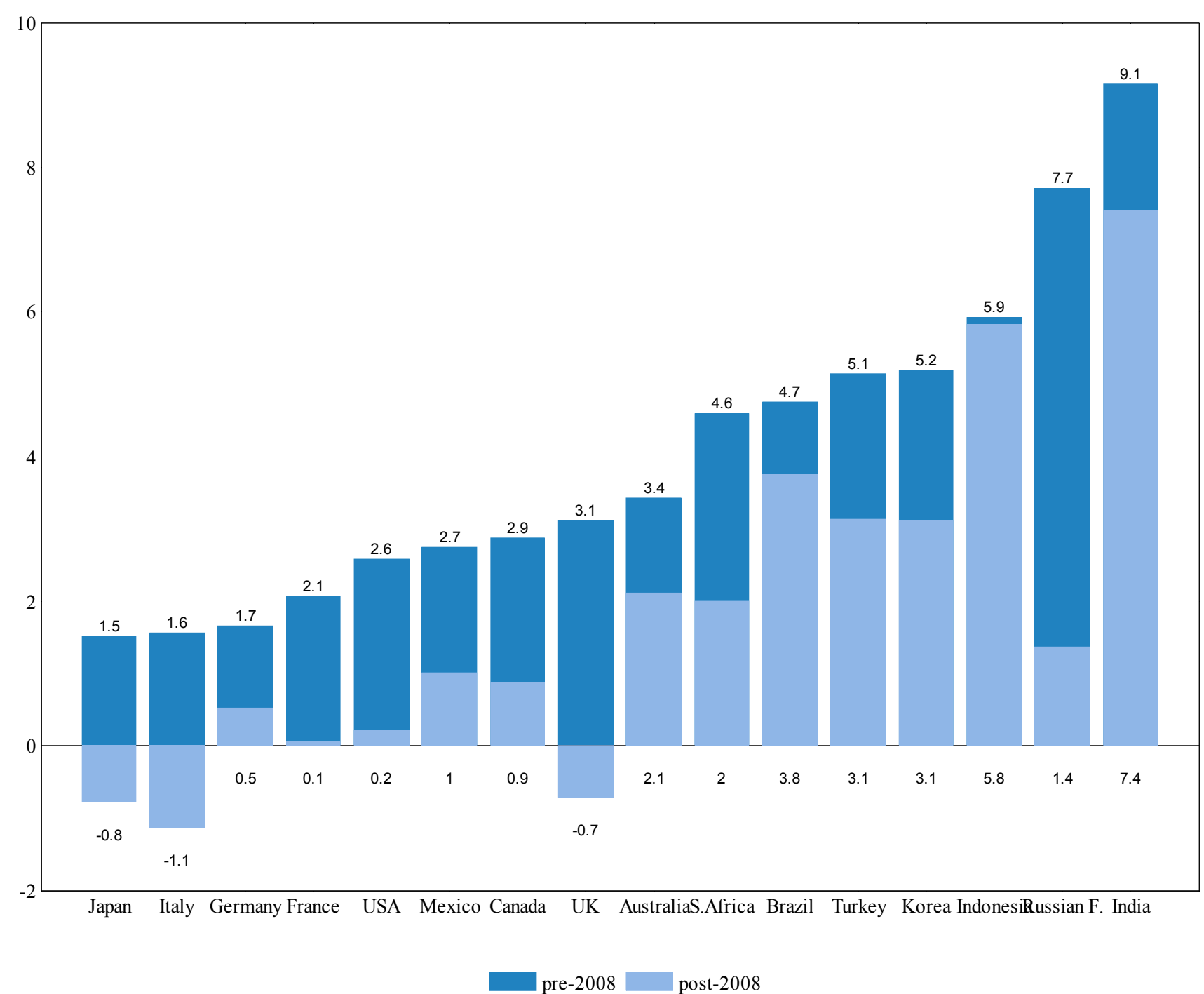


Figure I.2. Mean Absolute Revision to GDP $q / q-4$ Growth Rates (in percent):

First Estimate vs. Two-Year Estimate
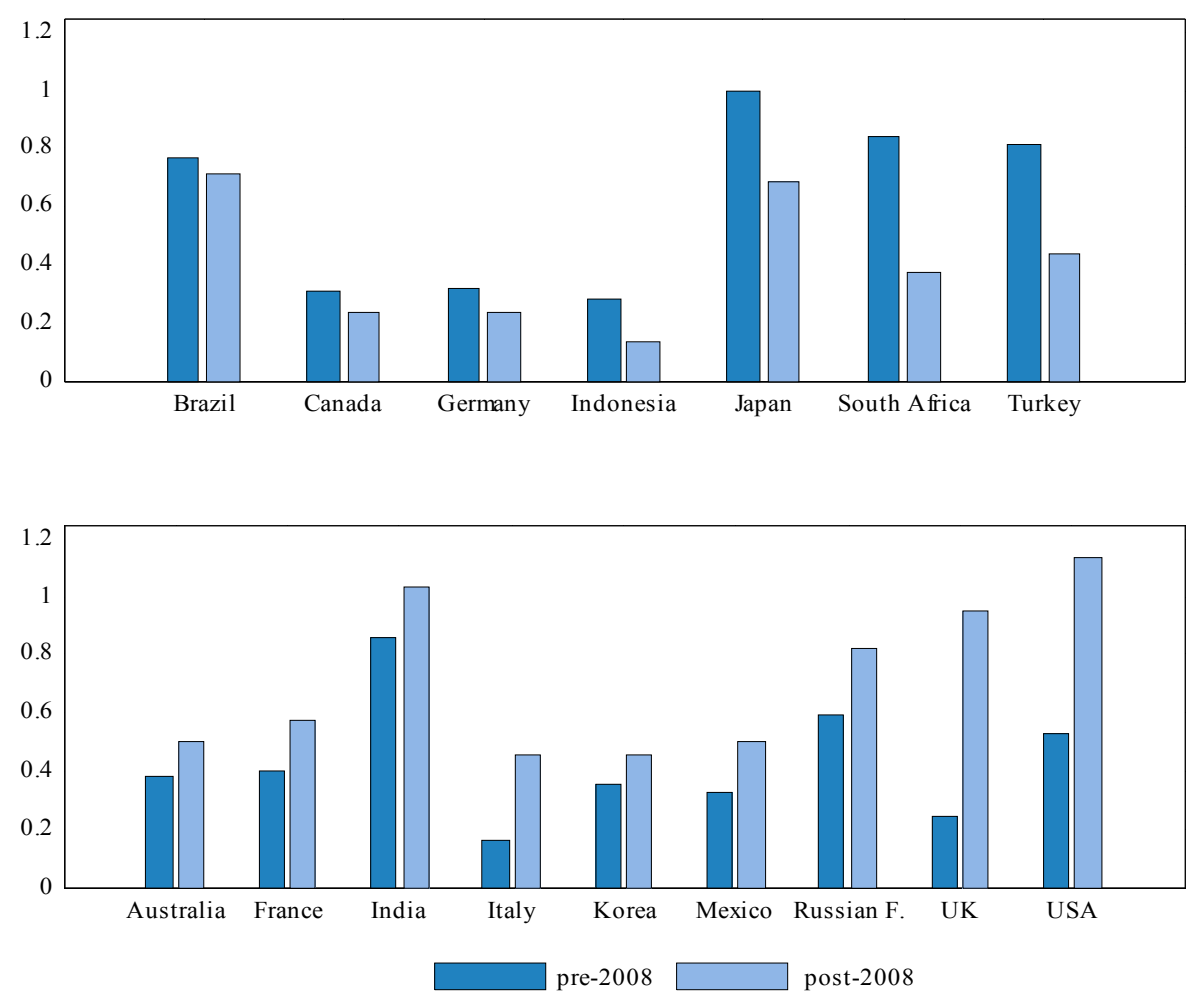

Figure I.3. Scatter Plot of Mean Absolute Revision to GDP q/q-4 Growth Rates (in percent):

First Estimate vs. Two-Year Estimate

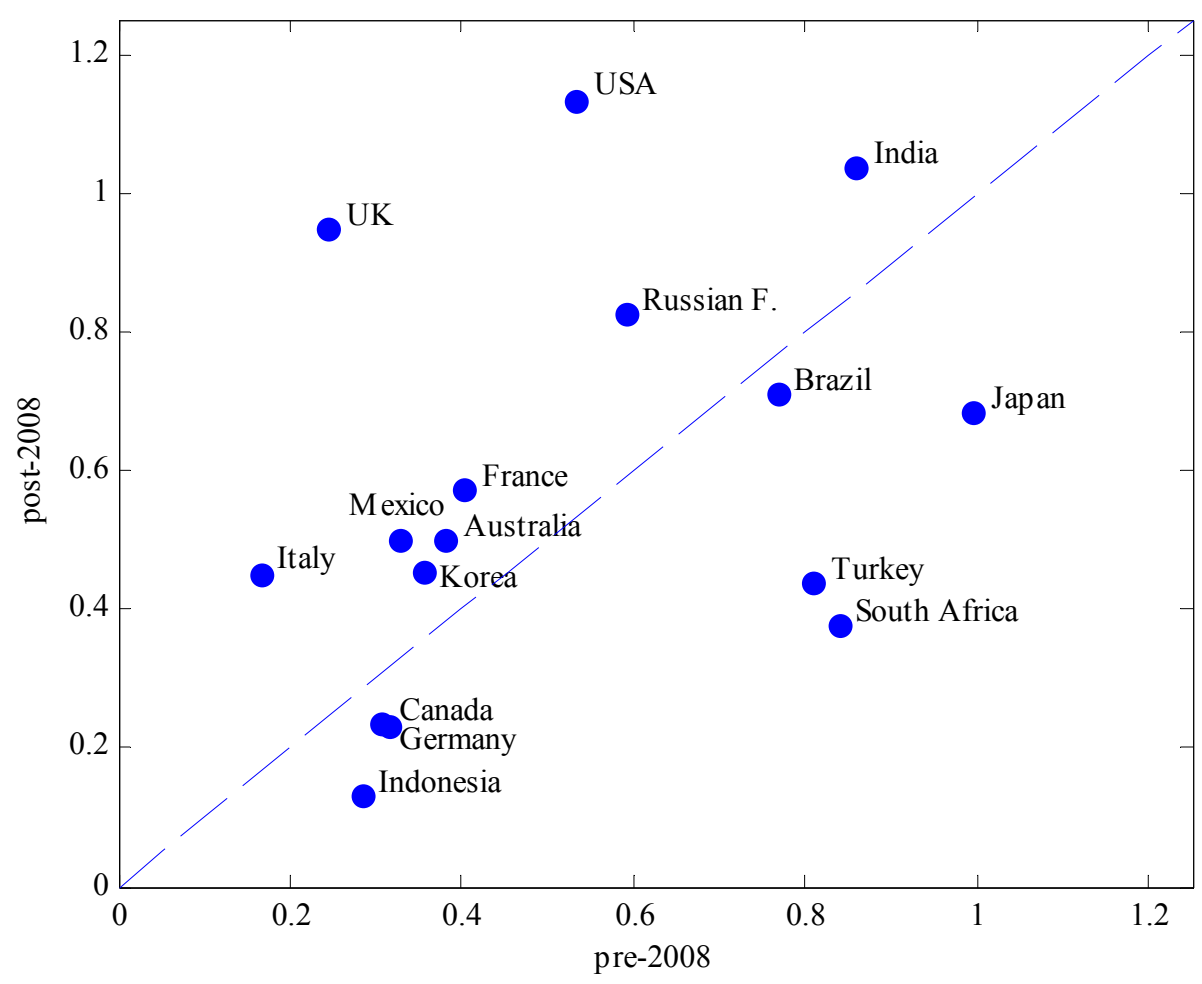

CInternational Monetary Fund. Not for Redistribution 
Figure I.4. Mean Revision to GDP $q / q-4$ Growth Rates (in percent): First Estimate vs. Two-Year Estimate

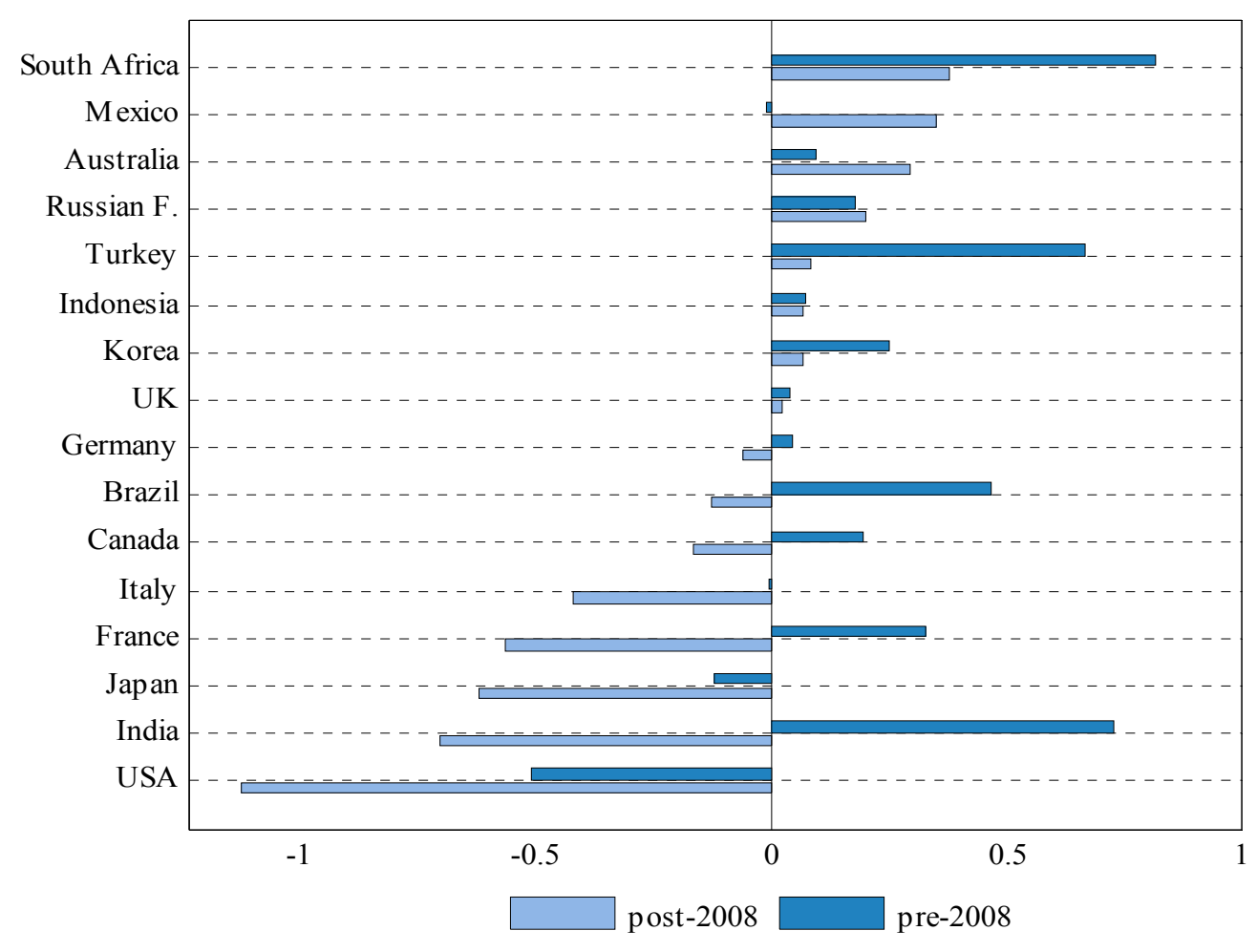

CInternational Monetary Fund. Not for Redistribution 
Figure I.5. U.S.A.: GDP q/q-4 Growth Rates of 2008 and 2009 Quarters Over Time

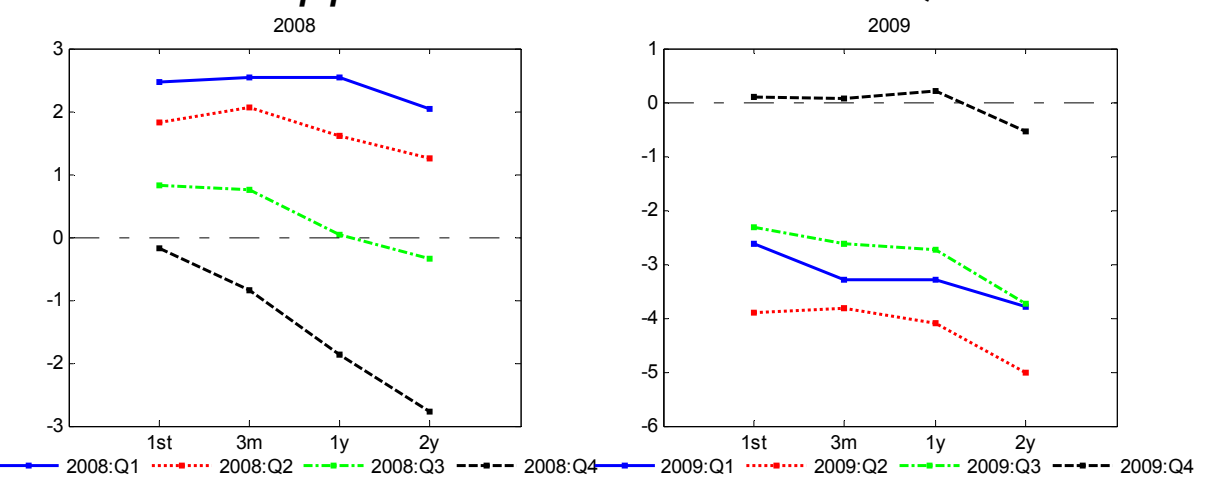

Figure I.6. U.K.: GDP q/q-4 Growth Rates of 2008 and 2009 Quarters Over Time
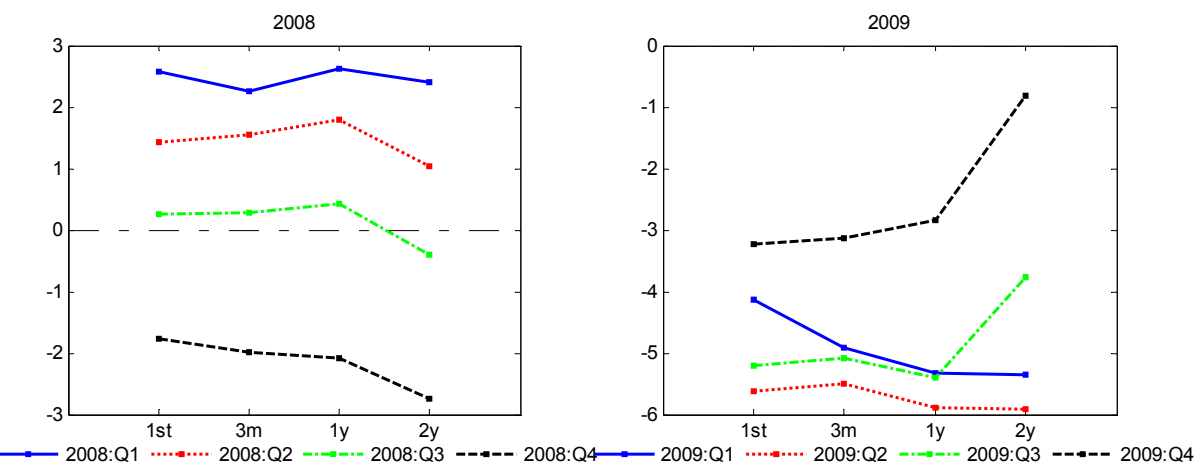

Figure I.7. Canada: GDP q/q-4 Growth Rates of 2008 and 2009 Quarters Over Time
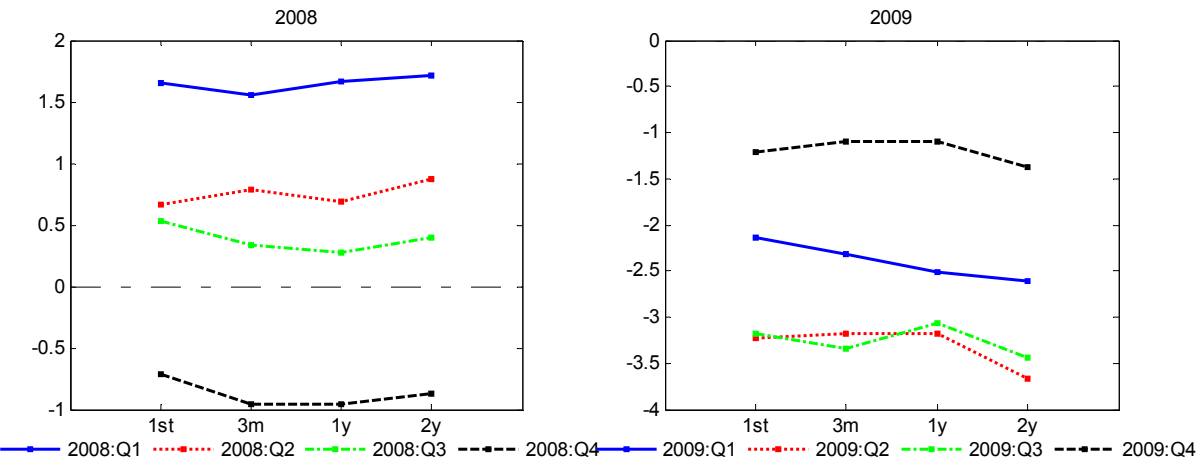

Figure I.8. Germany: GDP q/q-4 Growth Rates of 2008 and 2009 Quarters Over Time
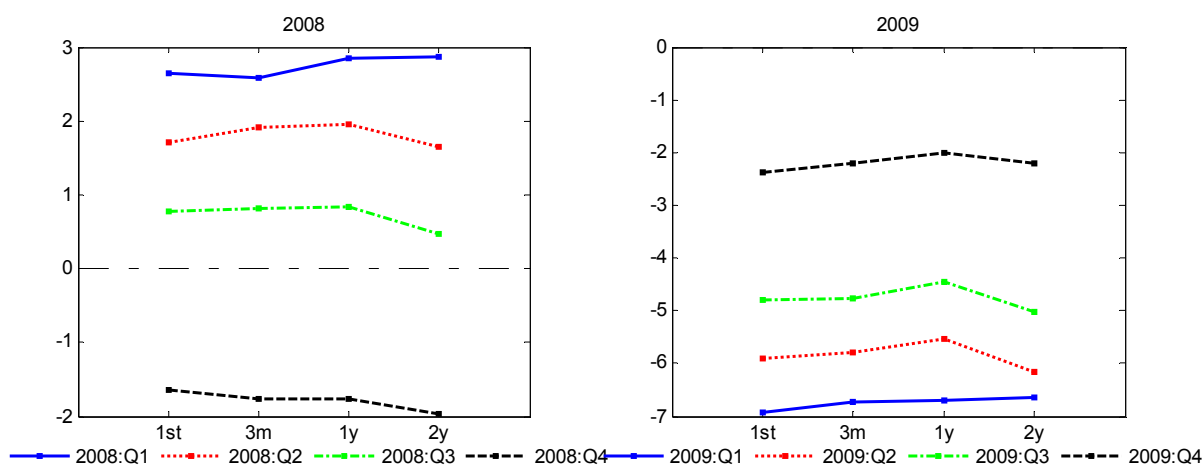

CInternational Monetary Fund. Not for Redistribution 
Table I.3 Percentage of Times Indicating Same Direction of Growth

\begin{tabular}{|c|c|c|c|c|c|c|}
\hline & \multicolumn{3}{|c|}{ pre-2008 } & \multicolumn{3}{|c|}{ post-2008 } \\
\hline & \multicolumn{3}{|c|}{$\begin{array}{c}\text { Success in indicating direction of } \\
\text { change }\end{array}$} & \multicolumn{3}{|c|}{$\begin{array}{c}\text { Success in indicating direction of } \\
\text { change }\end{array}$} \\
\hline & $3 m-1 s t$ & $1 y-1 s t$ & $2 y-1 s t$ & $3 m-1 s t$ & $1 \mathrm{y}-1 \mathrm{st}$ & $2 y-1 s t$ \\
\hline Australia & $100 \%$ & $100 \%$ & $100 \%$ & $100 \%$ & $100 \%$ & $100 \%$ \\
\hline Canada & $97 \%$ & $100 \%$ & $97 \%$ & $100 \%$ & $88 \%$ & $88 \%$ \\
\hline France & $90 \%$ & $94 \%$ & $90 \%$ & $100 \%$ & $100 \%$ & $88 \%$ \\
\hline Germany & $100 \%$ & $94 \%$ & $90 \%$ & $100 \%$ & $100 \%$ & $100 \%$ \\
\hline Italy & $90 \%$ & $90 \%$ & $94 \%$ & $100 \%$ & $100 \%$ & $100 \%$ \\
\hline Japan & $81 \%$ & $84 \%$ & $81 \%$ & $100 \%$ & $100 \%$ & $88 \%$ \\
\hline U.K. & $97 \%$ & $100 \%$ & $100 \%$ & $100 \%$ & $88 \%$ & $75 \%$ \\
\hline U.S.A. & $100 \%$ & $90 \%$ & $94 \%$ & $100 \%$ & $88 \%$ & $88 \%$ \\
\hline
\end{tabular}

Table I.4 Percentage of Times Indicating Acceleration or Deceleration

\begin{tabular}{|c|c|c|c|c|c|c|}
\hline & \multicolumn{3}{|c|}{ pre-2008 } & \multicolumn{3}{|c|}{ post-2008 } \\
\hline & \multicolumn{3}{|c|}{$\begin{array}{c}\text { Success in indicating acceleration or } \\
\text { deceleration }\end{array}$} & \multicolumn{3}{|c|}{$\begin{array}{c}\text { Success in indicating acceleration } \\
\text { or deceleration }\end{array}$} \\
\hline & $3 m-1 s t$ & $1 y-1 s t$ & $2 y-1 s t$ & $3 m-1 s t$ & $1 y-1 s t$ & $2 y-1 s$ \\
\hline Australia & $87 \%$ & $84 \%$ & $61 \%$ & $100 \%$ & $75 \%$ & $38 \%$ \\
\hline Canada & $100 \%$ & $100 \%$ & $97 \%$ & $87 \%$ & $88 \%$ & $75 \%$ \\
\hline France & $97 \%$ & $97 \%$ & $94 \%$ & $100 \%$ & $100 \%$ & $100 \%$ \\
\hline Germany & $97 \%$ & $97 \%$ & $97 \%$ & $87 \%$ & $100 \%$ & $100 \%$ \\
\hline Italy & $100 \%$ & $100 \%$ & $97 \%$ & $100 \%$ & $88 \%$ & $88 \%$ \\
\hline Japan & $90 \%$ & $77 \%$ & $74 \%$ & $100 \%$ & $88 \%$ & $100 \%$ \\
\hline U.K. & $100 \%$ & $100 \%$ & $100 \%$ & $93 \%$ & $100 \%$ & $100 \%$ \\
\hline U.S.A. & $97 \%$ & $94 \%$ & $97 \%$ & $93 \%$ & $88 \%$ & $88 \%$ \\
\hline
\end{tabular}




\section{Appendix II. Revisions Analysis of GDP: Country Tables and Charts}

\section{Australia}

Table II.1. Australia: Statistics on Revisions to GDP Growth Rates (before and after 2008)

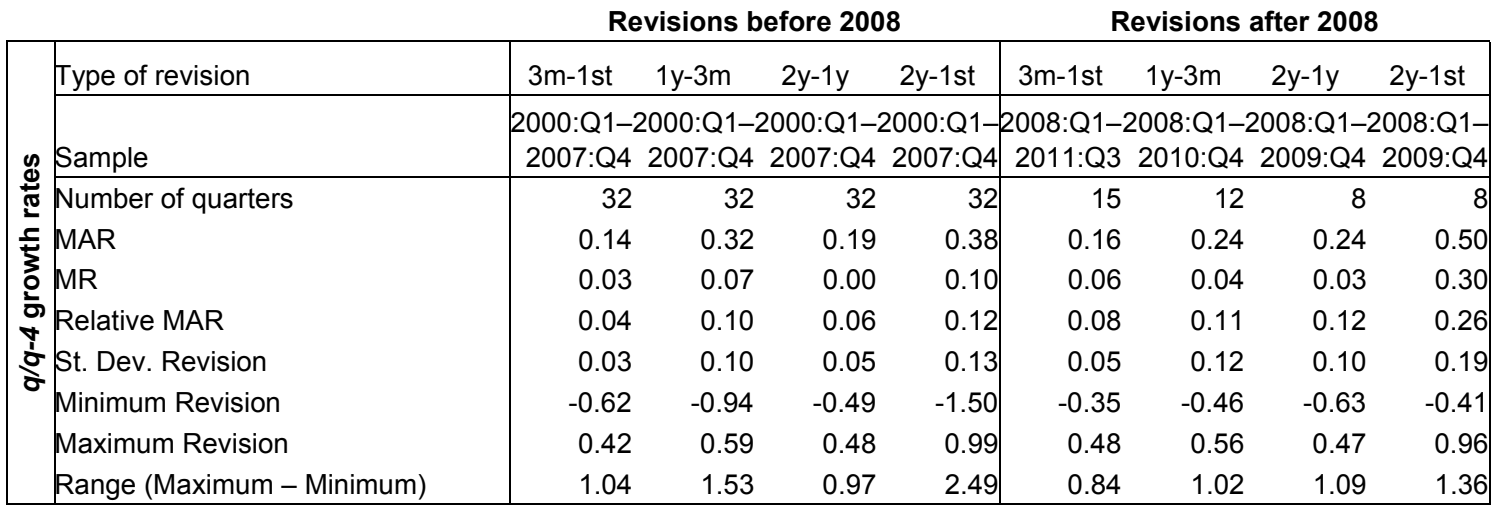

Figure II.1a. Australia: MAR and MR to GDP $q / q-4$ Growth Rates (before and after 2008)
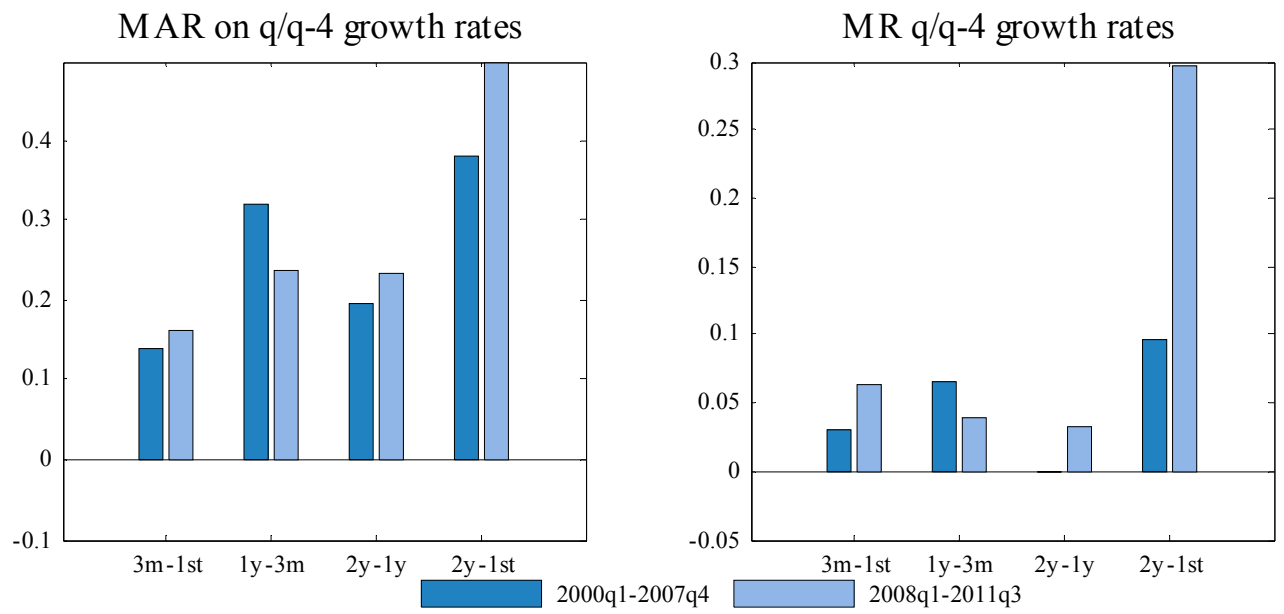

Figure II.1b. Australia: GDP q/q-4 Rates by Vintage of Publication

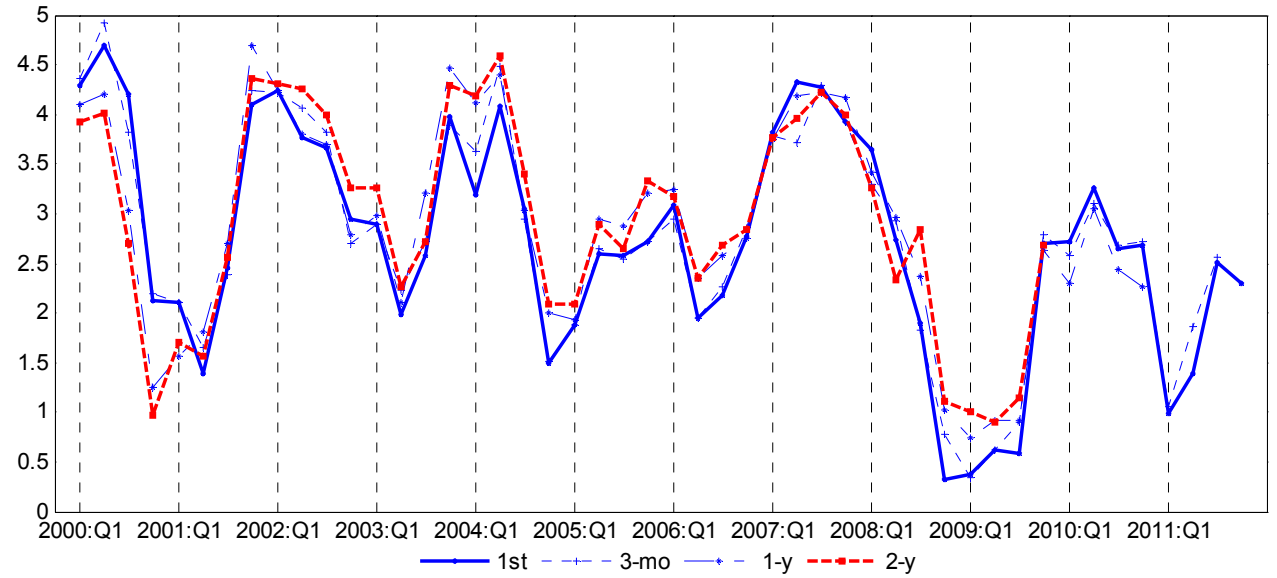

CInternational Monetary Fund. Not for Redistribution 


\section{BRAZIL}

Table II.2. Brazil: Statistics on Revisions to GDP Growth Rates (before and after 2008)

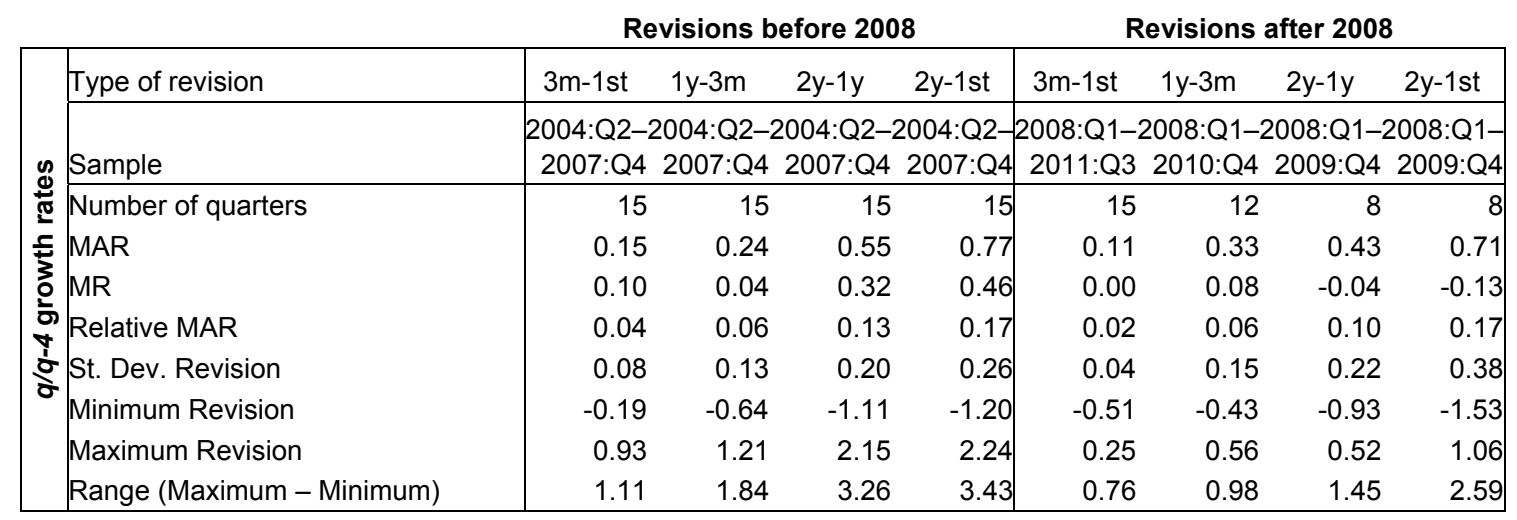

Figure II.2a. Brazil: MAR and MR to GDP q/q-4 Growth Rates (before and after 2008)
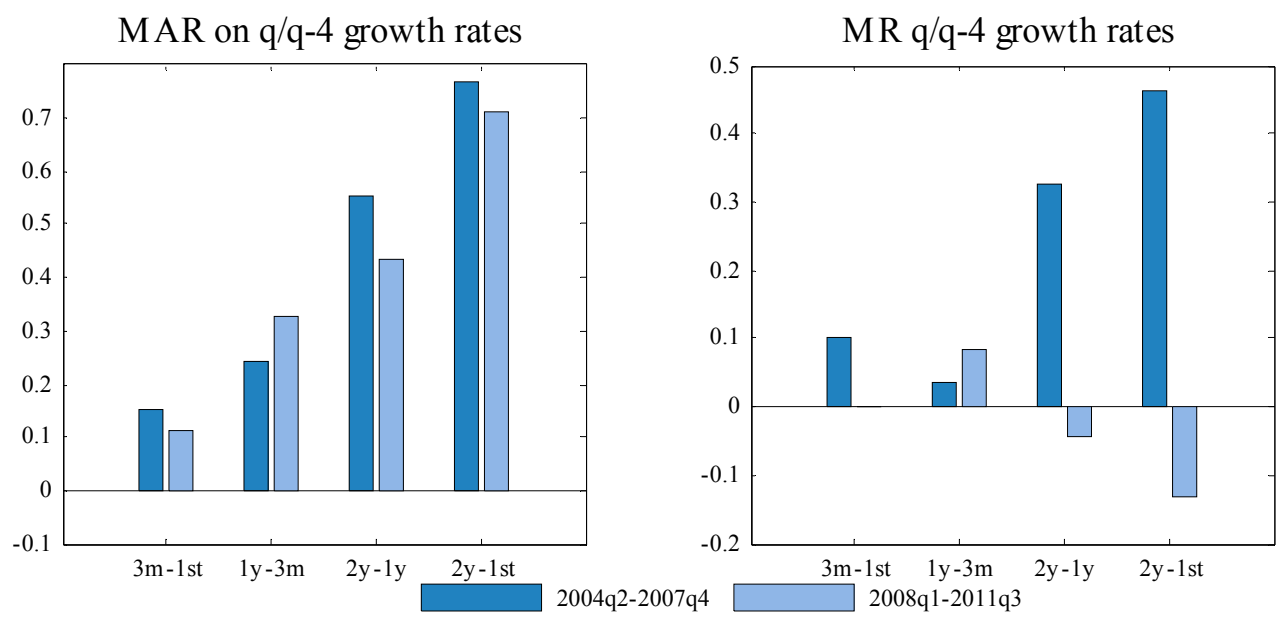

Figure II.2b. Brazil: GDP q/q-4 Rates by Vintage of Publication

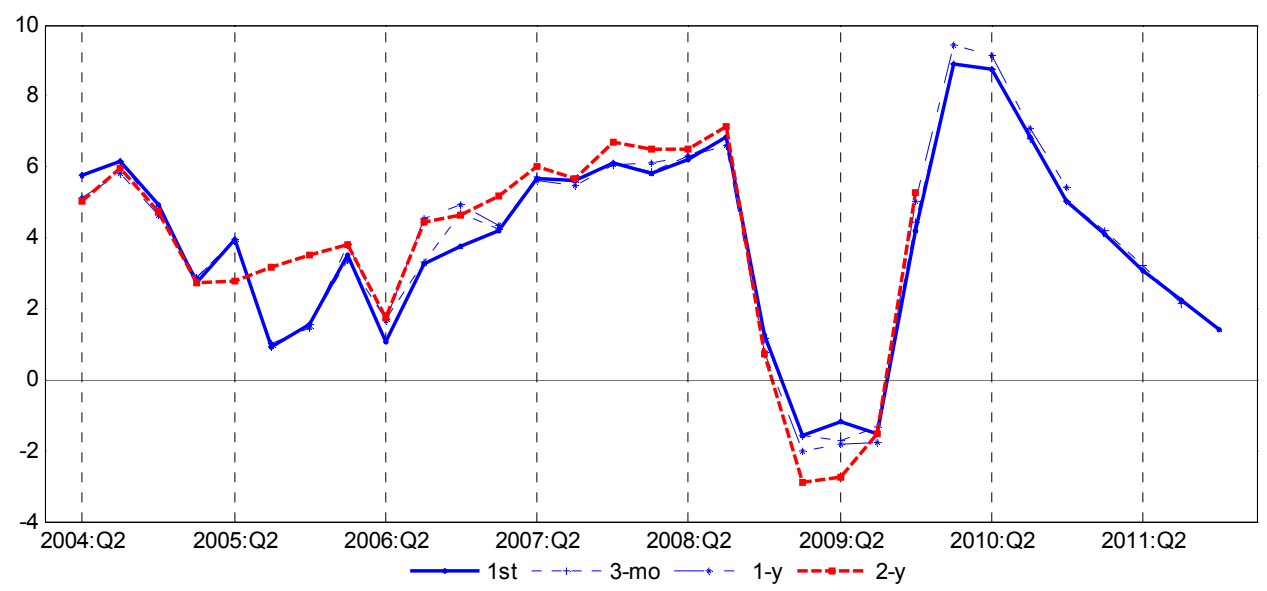

CInternational Monetary Fund. Not for Redistribution 


\section{Canada}

Table II.3. Canada: Statistics on Revisions to GDP Growth Rates (before and after 2008)

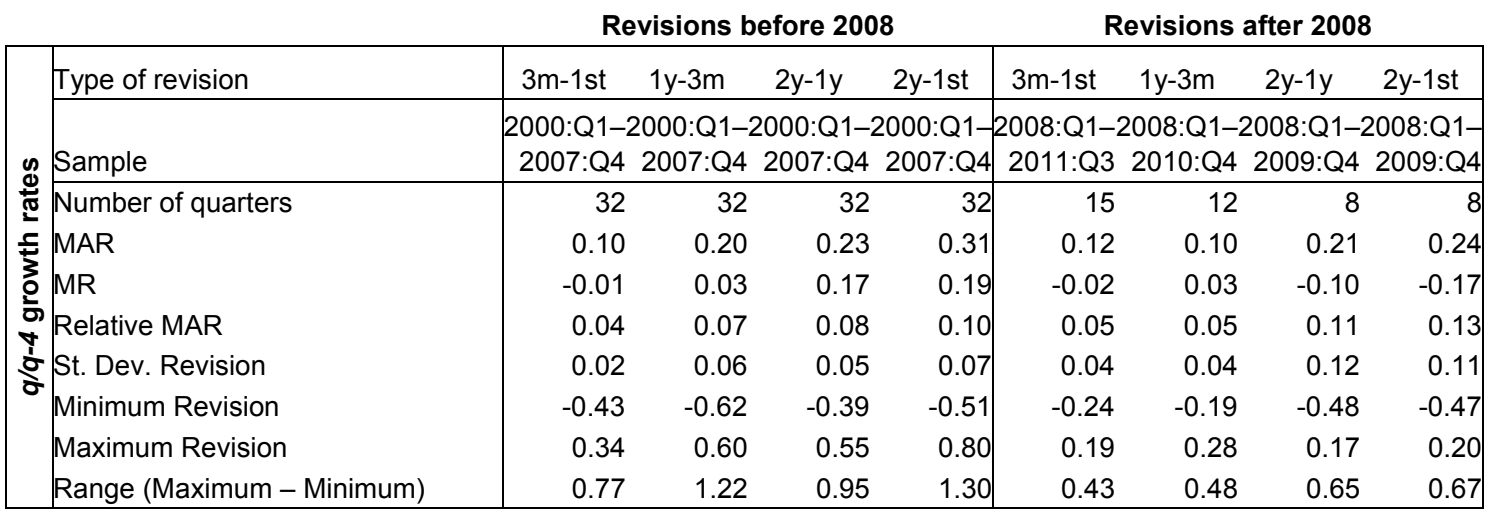

Figure II.3a. Canada: MAR and MR to GDP q/q-4 Growth Rates (before and after 2008)

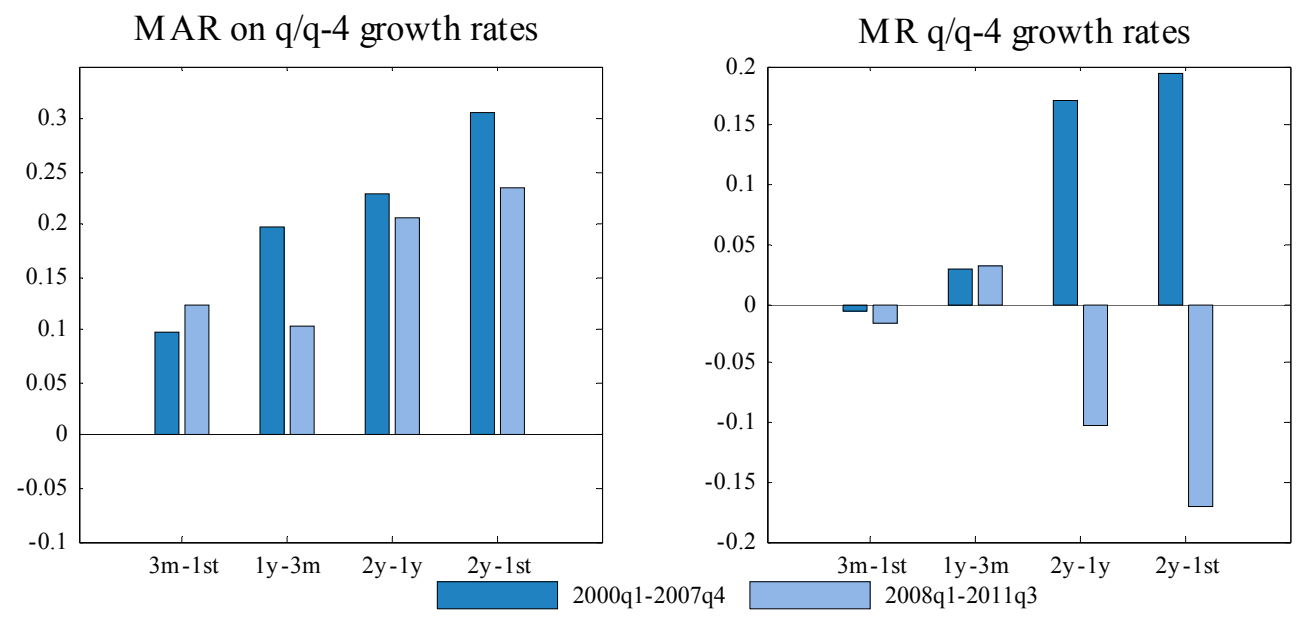

Figure II.3b. Canada: GDP q/q-4 Rates by Vintage of Publication

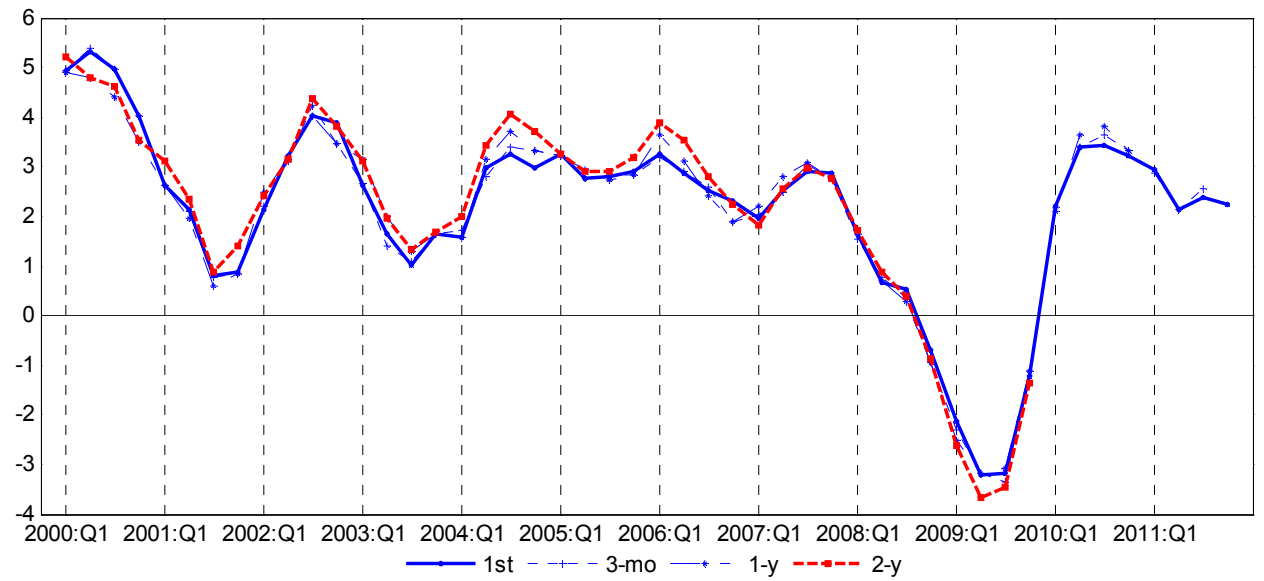

CInternational Monetary Fund. Not for Redistribution 
FranCE

Table II.4. France: Statistics on Revisions to GDP Growth Rates (before and after 2008)

\begin{tabular}{|c|c|c|c|c|c|c|c|c|c|}
\hline & & & visions b & efore 200 & & & evisions & after 2008 & \\
\hline & Type of revision & $3 m-1 s t$ & $1 y-3 m$ & $2 y-1 y$ & $2 y-1 s t$ & $3 m-1 s t$ & $1 y-3 m$ & $2 y-1 y$ & $2 y-1 s t$ \\
\hline \& & Sample & $\begin{array}{r}2000: Q 1- \\
2007: Q 4 \\
\end{array}$ & $\begin{array}{l}2000: Q 1-2 \\
2007: Q 4\end{array}$ & $\begin{array}{l}\text { 2000:Q1- } \\
2007: \text { Q4 }\end{array}$ & $\begin{array}{l}2000: Q 1- \\
2007: Q 4\end{array}$ & \begin{tabular}{|l} 
2008:Q1- \\
2011:Q3
\end{tabular} & $\begin{array}{r}2008: Q 1- \\
2010: Q 4\end{array}$ & $\begin{array}{c}\text { 2008:Q1-2 } \\
\text { 2009:Q4 }\end{array}$ & $\begin{array}{r}\text { 2008:Q1- } \\
\text { 2009:Q4 } \\
\end{array}$ \\
\hline సँّ & Number of quarters & 32 & 32 & 32 & 32 & 15 & 12 & 8 & 8 \\
\hline$\xi$ & MAR & 0.13 & 0.23 & 0.30 & 0.40 & 0.14 & 0.21 & 0.14 & 0.57 \\
\hline 3 & MR & 0.00 & 0.07 & 0.25 & 0.33 & -0.11 & -0.21 & -0.14 & -0.57 \\
\hline वे & Relative MAR & 0.07 & 0.13 & 0.14 & 0.19 & 0.08 & 0.12 & 0.07 & 0.30 \\
\hline & St. Dev. Revision & 0.03 & 0.06 & 0.07 & 0.10 & 0.05 & 0.05 & 0.05 & 0.10 \\
\hline & Minimum Revision & -0.60 & -0.38 & -0.35 & -0.38 & -0.69 & -0.52 & -0.31 & -0.99 \\
\hline & Maximum Revision & 0.53 & 0.69 & 0.94 & 1.29 & 0.07 & 0.00 & 0.01 & -0.31 \\
\hline & Range (Maximum - Minimum) & 1.13 & 1.07 & 1.30 & 1.67 & 0.76 & 0.52 & 0.32 & 0.68 \\
\hline
\end{tabular}

Figure II.4a. France: MAR and MR to GDP q/q-4 Growth Rates (before and after 2008)

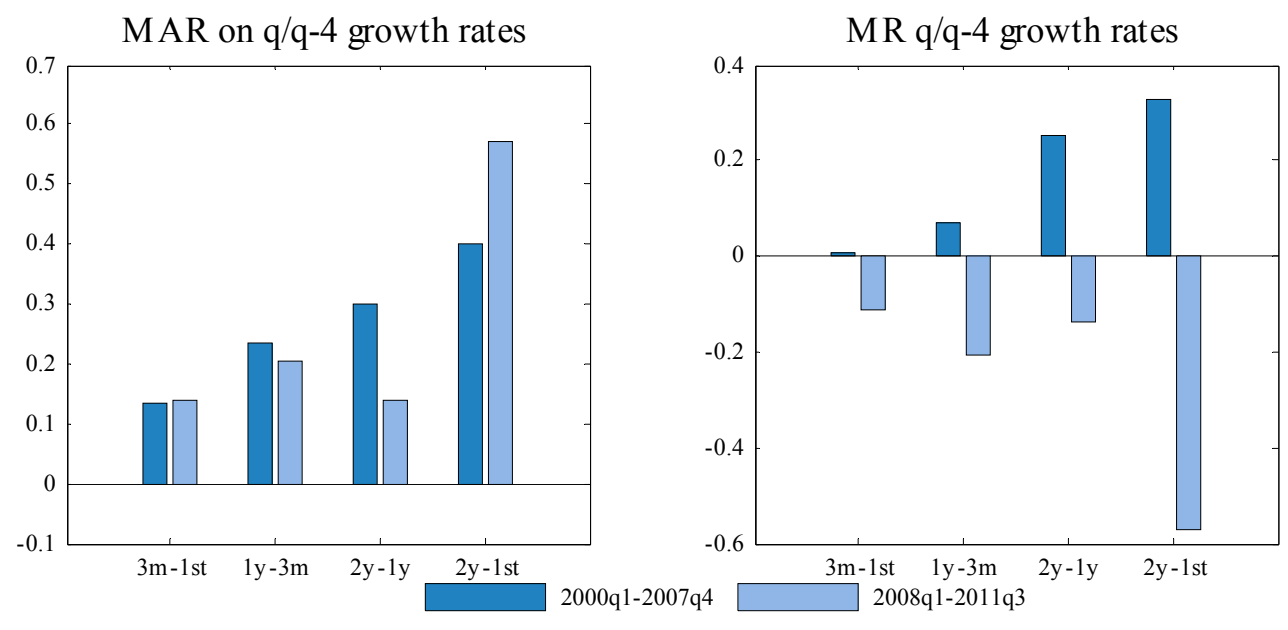

Figure II.4b. France: GDP q/q-4 Rates by Vintage of Publication

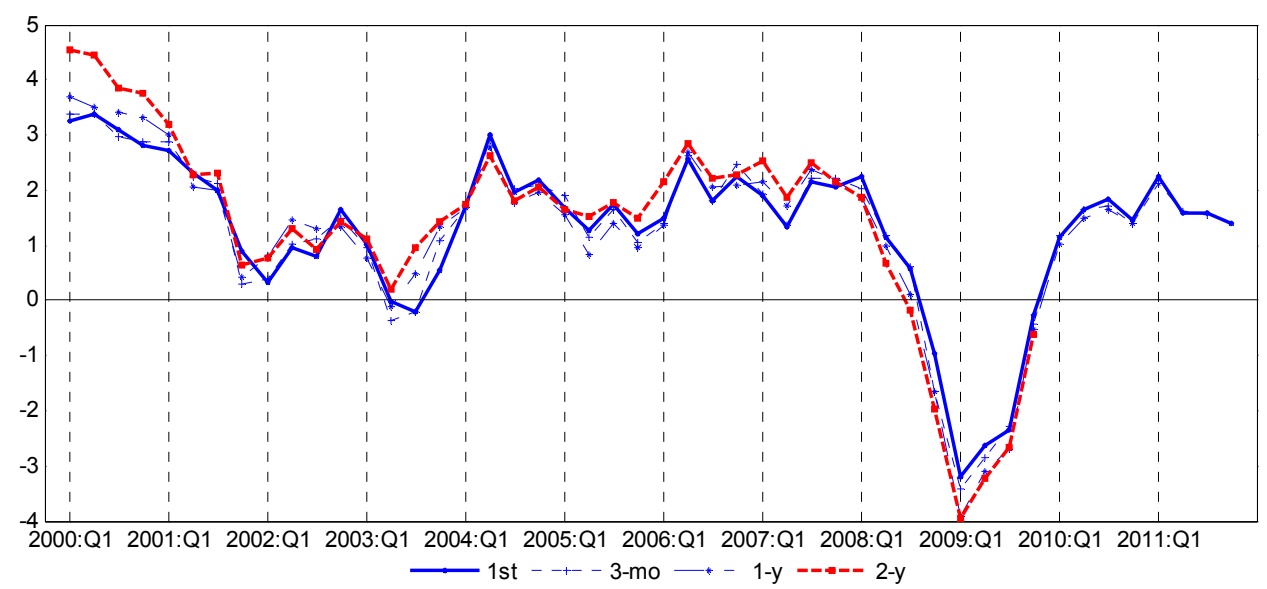

CInternational Monetary Fund. Not for Redistribution 


\section{GERMANY}

Table II.5. Germany: Statistics on Revisions to GDP Growth Rates (before and after 2008)

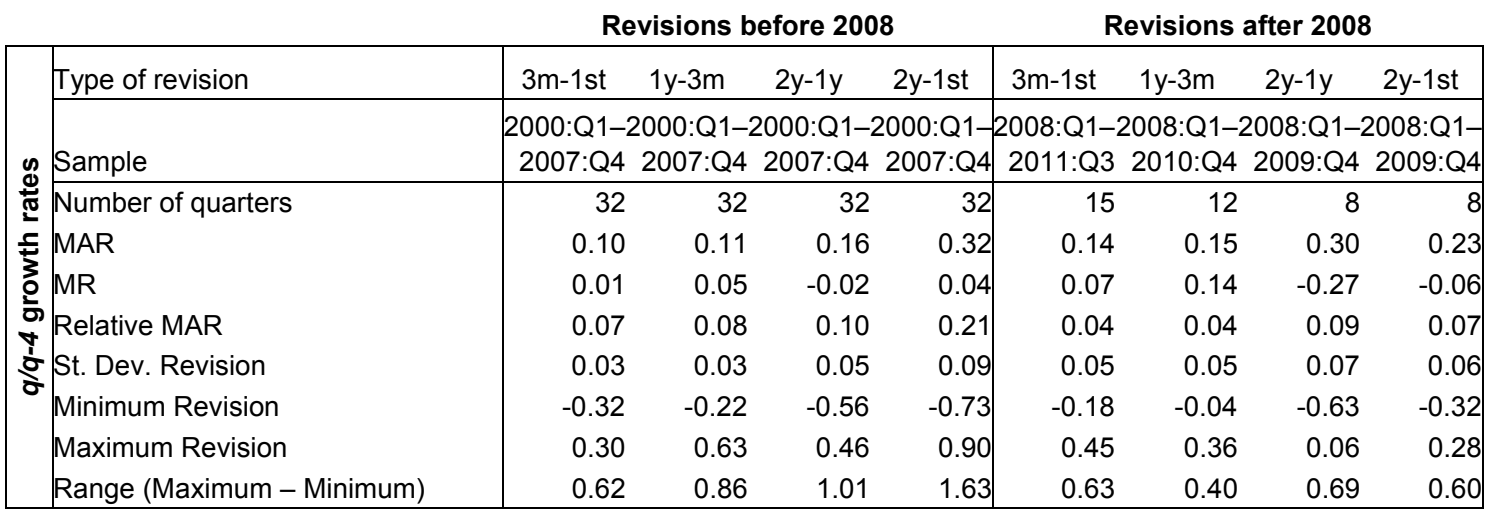

Figure II.5a. Germany: MAR and MR to GDP q/q-4 Growth Rates (before and after 2008)

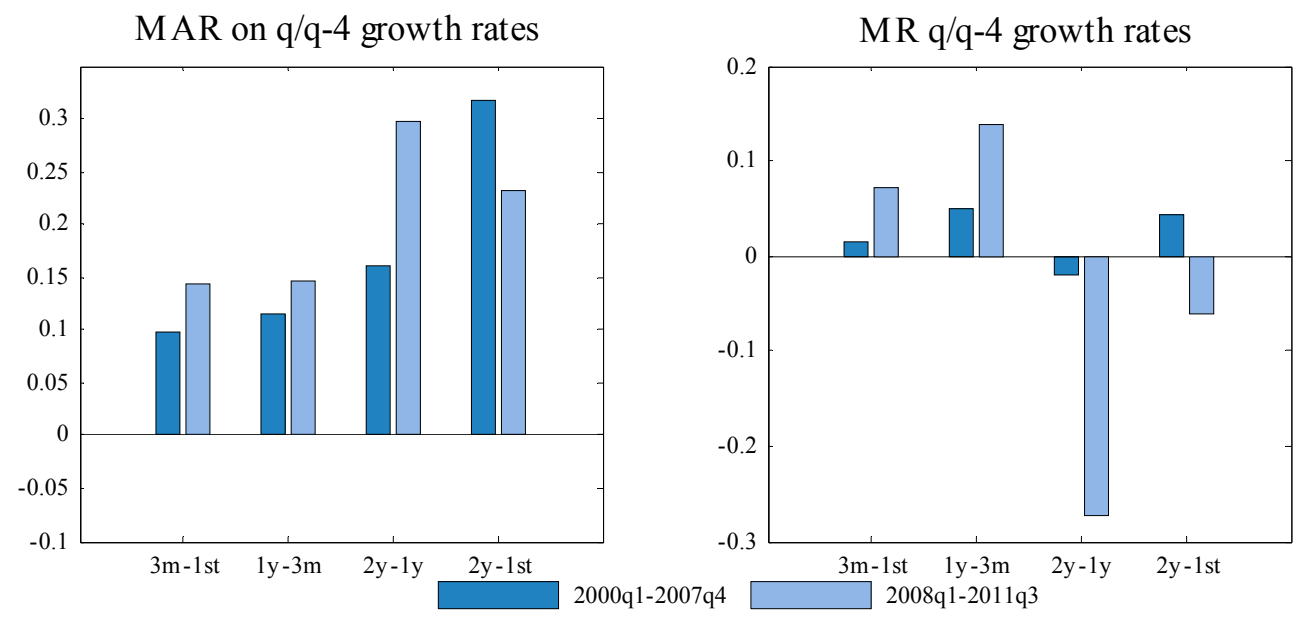

Figure II.5b. Germany: GDP $q / q-4$ Rates by Vintage of Publication

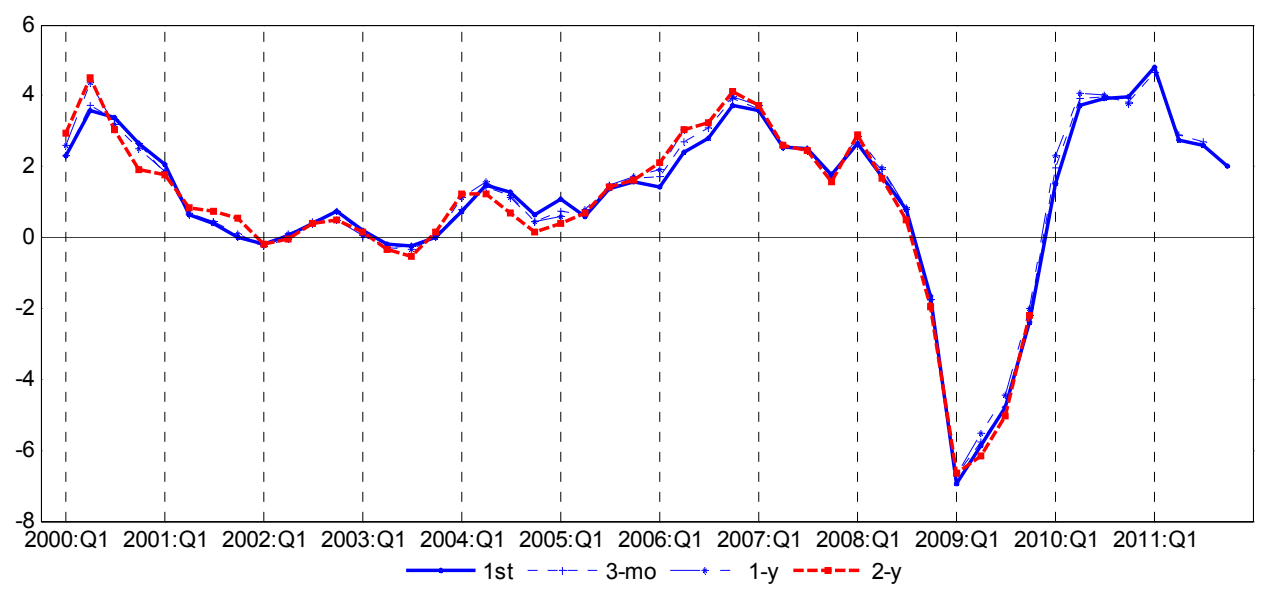

CInternational Monetary Fund. Not for Redistribution 


\section{INDIA}

Table II.6. India: Statistics on Revisions to GDP Growth Rates (before and after 2008)

\begin{tabular}{|c|c|c|c|c|c|c|c|c|c|}
\hline & & & visions b & efore 200 & & & evisions & ffter 2008 & \\
\hline & Type of revision & $3 m-1 s t$ & $1 y-3 m$ & $2 y-1 y$ & $2 y-1 s t$ & $3 m-1 s t$ & $1 y-3 m$ & $2 y-1 y$ & $2 y-1 s t$ \\
\hline \& & Sample & $\begin{array}{r}2004: Q 4- \\
2007: Q 4 \\
\end{array}$ & $\begin{array}{l}\text { 2004:Q4-2 } \\
\text { 2007:Q4 }\end{array}$ & $\begin{array}{l}2004: Q 4- \\
2007: Q 4\end{array}$ & $\begin{array}{r}2004: Q 4 \\
2007: Q 4\end{array}$ & $\begin{array}{r}\text { 2008:Q1- } \\
\text { 2010:Q1 }\end{array}$ & $\begin{array}{l}\text { 2008:Q1-2 } \\
\text { 2010:Q1 }\end{array}$ & $\begin{array}{l}\text { 008:Q1-2 } \\
\text { 2009:Q4 }\end{array}$ & $\begin{array}{r}\text { 2008:Q1- } \\
\text { 2009:Q4 } \\
\end{array}$ \\
\hline సँّ & Number of quarters & 13 & 13 & 13 & 13 & 9 & 9 & 8 & 8 \\
\hline$\xi$ & MAR & 0.06 & 0.70 & 0.44 & 0.86 & 0.22 & 0.51 & 0.42 & 1.04 \\
\hline 3 & MR & 0.03 & 0.68 & 0.02 & 0.73 & 0.18 & -0.48 & -0.37 & -0.71 \\
\hline ga & Relative MAR & 0.01 & 0.08 & 0.05 & 0.09 & 0.03 & 0.07 & 0.07 & 0.17 \\
\hline & St. Dev. Revision & 0.05 & 0.15 & 0.15 & 0.16 & 0.11 & 0.26 & 0.24 & 0.43 \\
\hline & Minimum Revision & -0.19 & -0.08 & -1.29 & -0.51 & -0.21 & -1.79 & -1.56 & -2.13 \\
\hline & Maximum Revision & 0.49 & 2.00 & 1.83 & 2.42 & 1.32 & 0.13 & 0.19 & 1.26 \\
\hline & Range (Maximum - Minimum) & 0.68 & 2.07 & 3.11 & 2.93 & 1.52 & 1.92 & 1.75 & 3.39 \\
\hline
\end{tabular}

Figure II.6a. India: MAR and MR to GDP q/q-4 Growth Rates (before and after 2008)
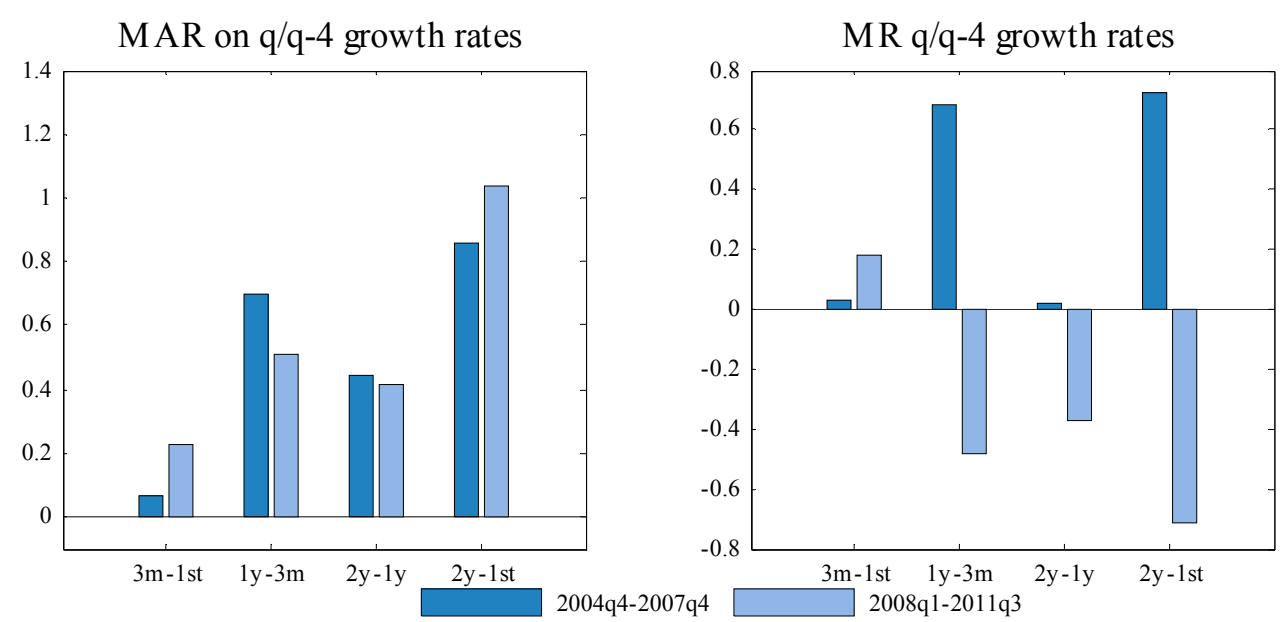

Figure II.6b. India: GDP q/q-4 Rates by Vintage of Publication

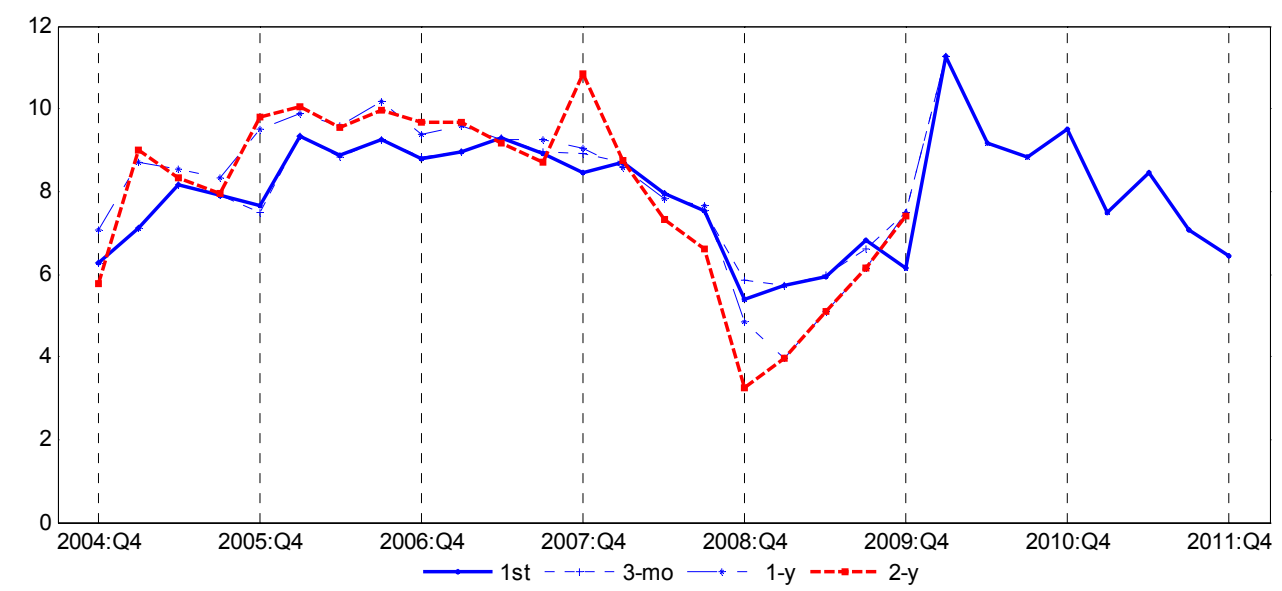




\section{INDONESIA}

Table II.7. Indonesia: Statistics on Revisions to GDP Growth Rates (before and after 2008)

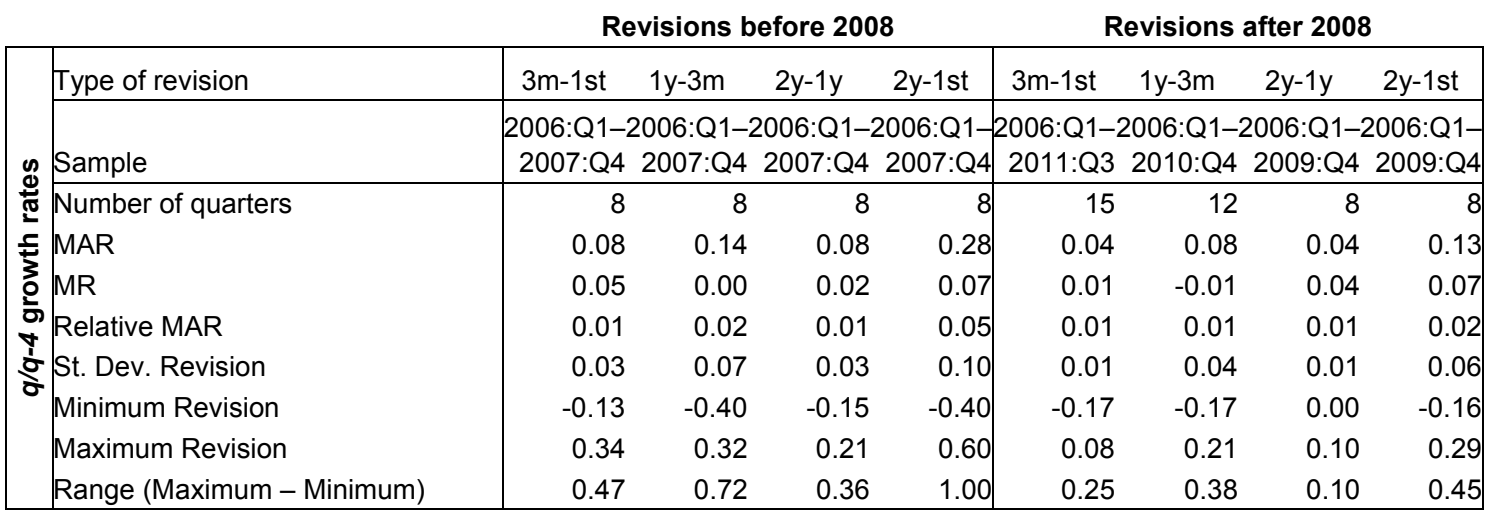

Figure II.7a. Indonesia: MAR and MR to GDP q/q-4 Growth Rates (before and after 2008)

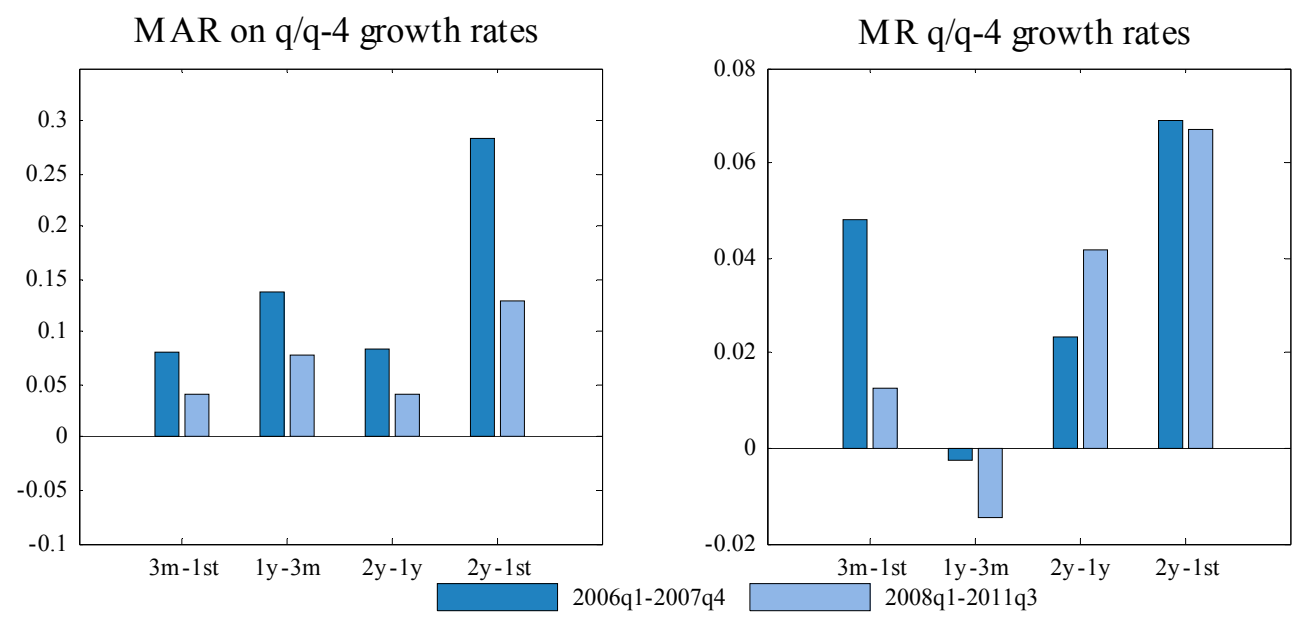

Figure II.7b. Indonesia: GDP q/q-4 Rates by Vintage of Publication

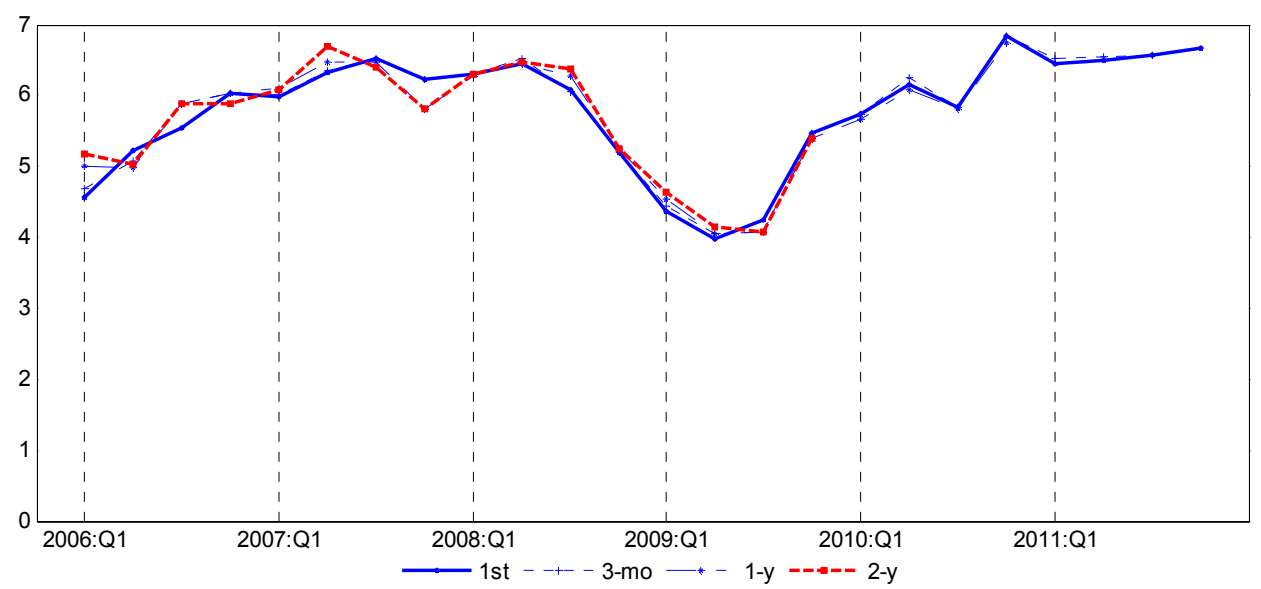




\section{ITALY}

Table II.8. Italy: Statistics on Revisions to GDP Growth Rates (before and after 2008)

\begin{tabular}{|c|c|c|c|c|c|c|c|c|c|}
\hline & & & visions b & efore 200 & & & evisions & after 2008 & \\
\hline & Type of revision & $3 m-1 s t$ & $1 y-3 m$ & $2 y-1 y$ & $2 y-1 s t$ & $3 m-1 s t$ & $1 y-3 m$ & $2 y-1 y$ & $2 y-1 s t$ \\
\hline \& & Sample & $\begin{array}{r}2000: Q 1- \\
2007: Q 4 \\
\end{array}$ & $\begin{array}{l}2000: Q 1- \\
2007: Q 4\end{array}$ & $\begin{array}{l}000: Q 1- \\
2007: Q 4\end{array}$ & $\begin{array}{r}2000: Q 1- \\
2007: Q 4\end{array}$ & \begin{tabular}{|l} 
2008:Q1- \\
2011:Q3
\end{tabular} & $\begin{array}{r}2008: Q 1- \\
2010: Q 4\end{array}$ & $\begin{array}{c}\text { 2008:Q1-2 } \\
\text { 2009:Q4 }\end{array}$ & $\begin{array}{r}\text { 2008:Q1- } \\
\text { 2009:Q4 } \\
\end{array}$ \\
\hline तٓ & Number of quarters & 32 & 32 & 32 & 32 & 15 & 12 & 8 & 8 \\
\hline そ & MAR & 0.08 & 0.11 & 0.10 & 0.16 & 0.13 & 0.17 & 0.24 & 0.45 \\
\hline$=$ & MR & 0.01 & -0.01 & 0.00 & -0.01 & 0.00 & -0.01 & -0.24 & -0.43 \\
\hline वे & Relative MAR & 0.06 & 0.09 & 0.08 & 0.13 & 0.06 & 0.07 & 0.07 & 0.14 \\
\hline & St. Dev. Revision & 0.02 & 0.03 & 0.02 & 0.05 & 0.06 & 0.07 & 0.05 & 0.14 \\
\hline & Minimum Revision & -0.25 & -0.34 & -0.31 & -0.55 & -0.43 & -0.48 & -0.47 & -0.88 \\
\hline & Maximum Revision & 0.26 & 0.30 & 0.45 & 0.42 & 0.27 & 0.20 & -0.14 & 0.10 \\
\hline & Range (Maximum - Minimum) & 0.51 & 0.64 & 0.75 & 0.96 & 0.69 & 0.68 & 0.33 & 0.98 \\
\hline
\end{tabular}

Figure II.8a. Italy: MAR and MR to GDP q/q-4 Growth Rates (before and after 2008)

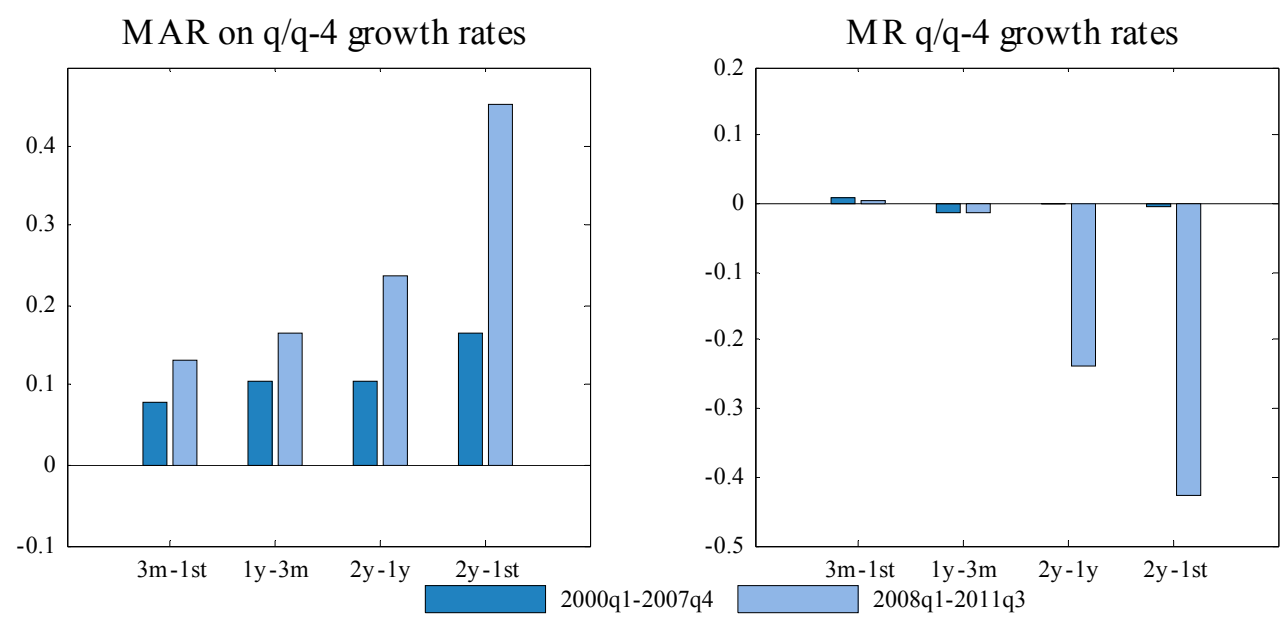

Figure II.8b. Italy: GDP q/q-4 Rates by Vintage of Publication

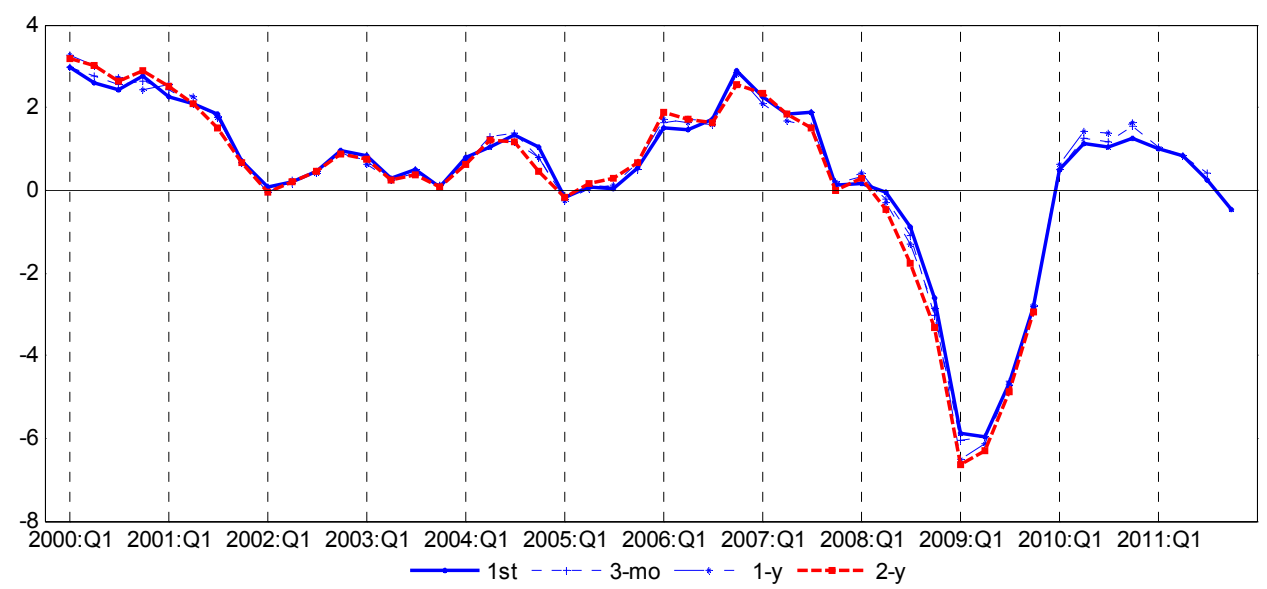

CInternational Monetary Fund. Not for Redistribution 


\section{JAPAN}

Table II.9. Japan: Statistics on Revisions to GDP Growth Rates (before and after 2008)

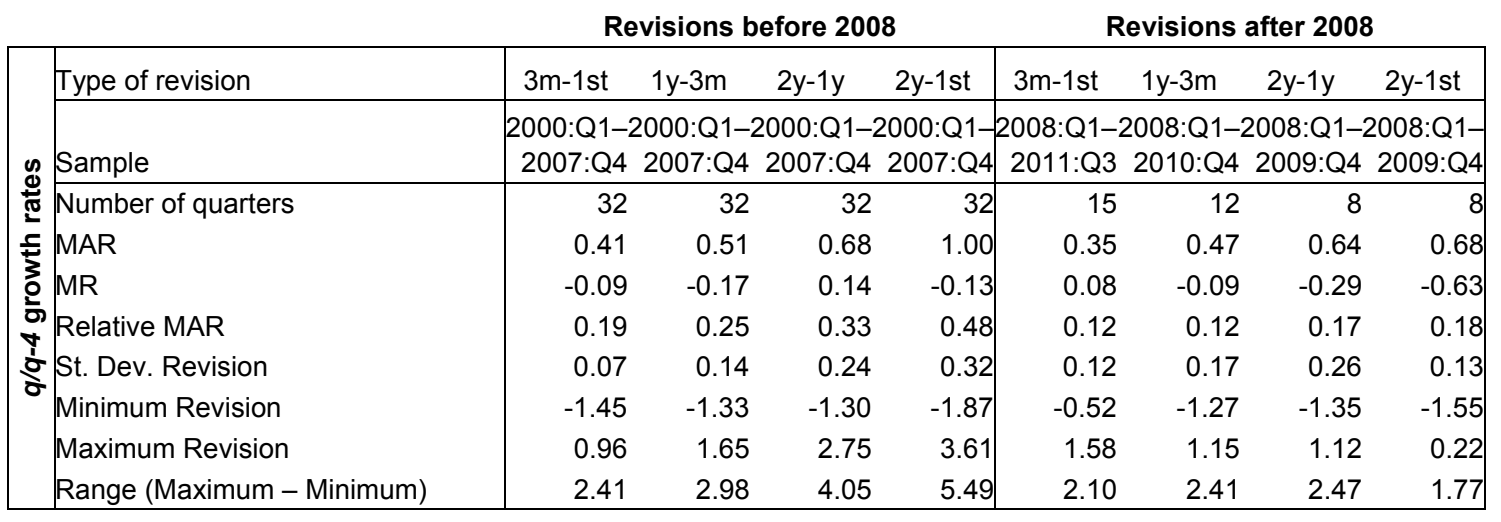

Figure II.9a. Japan: MAR and MR to GDP q/q-4 Growth Rates (before and after 2008)
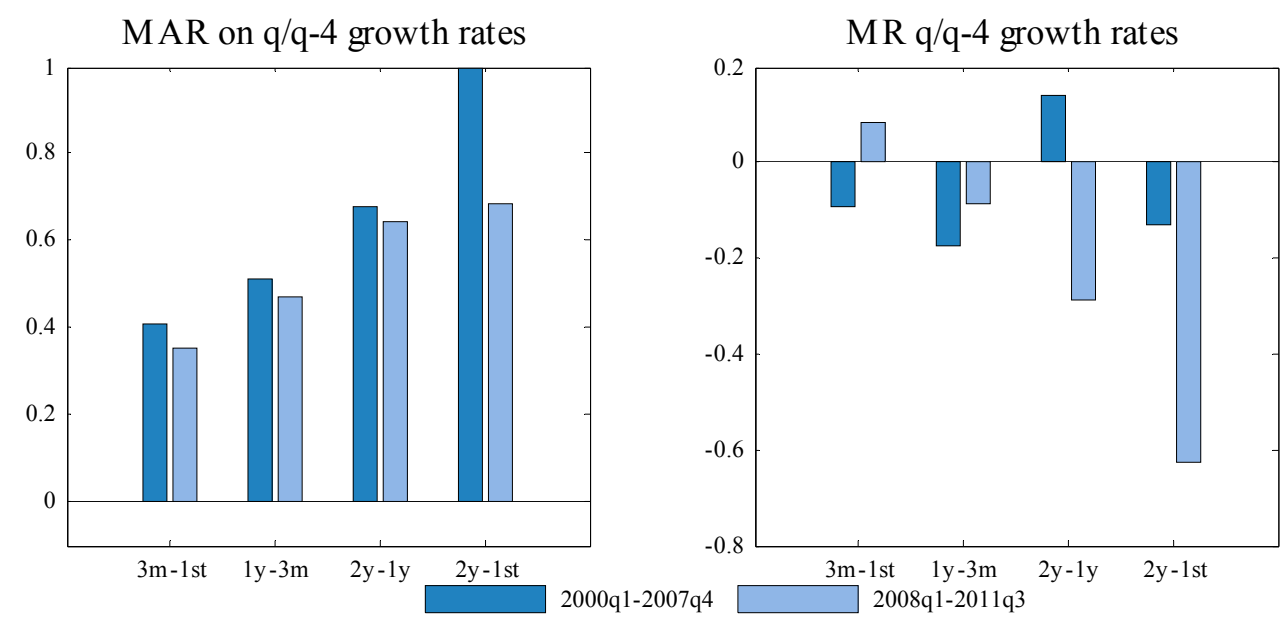

Figure II.9b. Japan: GDP q/q-4 Rates by Vintage of Publication

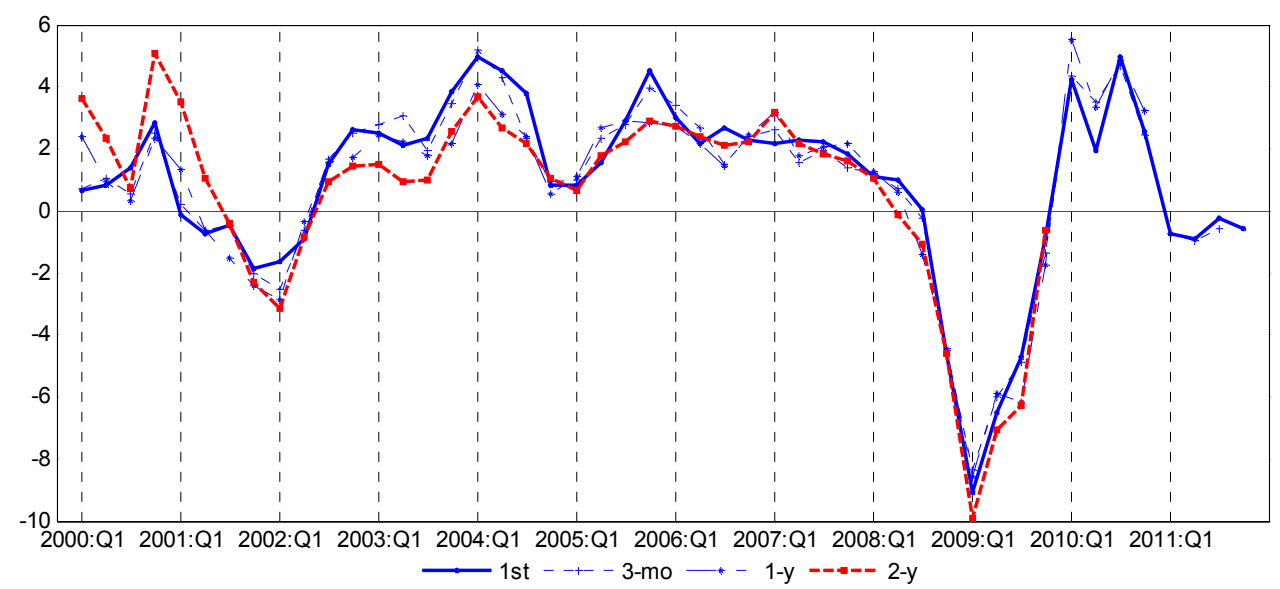

CInternational Monetary Fund. Not for Redistribution 


\section{KOREA}

Table II.10. Korea: Statistics on Revisions to GDP Growth Rates (before and after 2008)

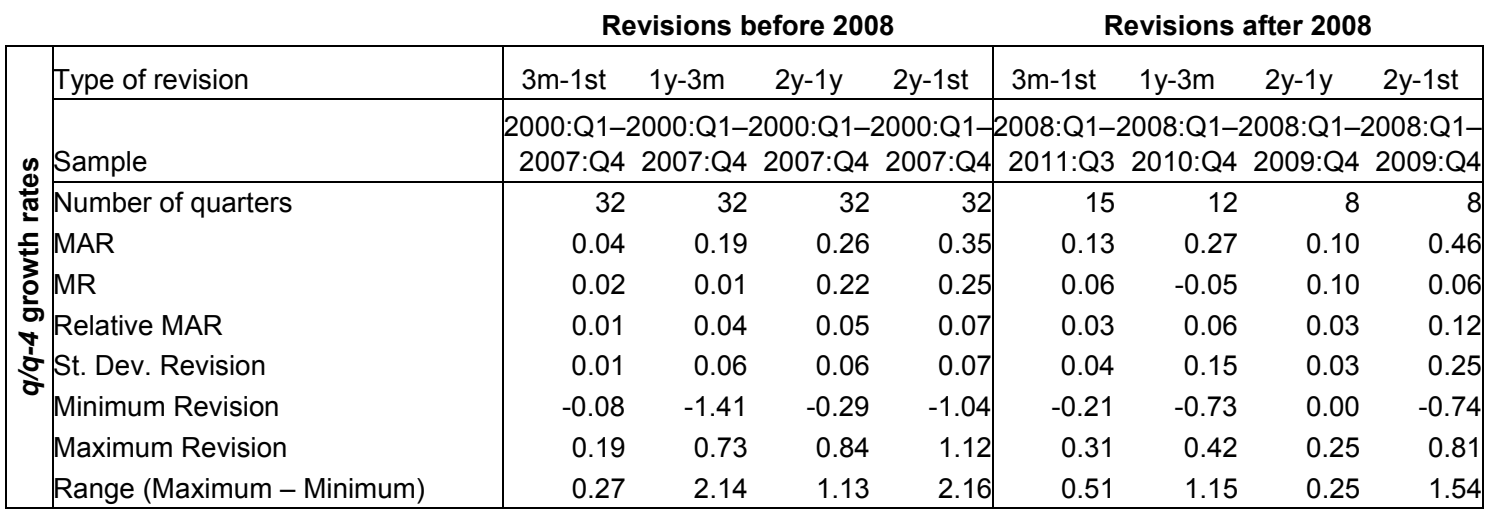

Figure II.10a. Korea: MAR and MR to GDP q/q-4 Growth Rates (before and after 2008)

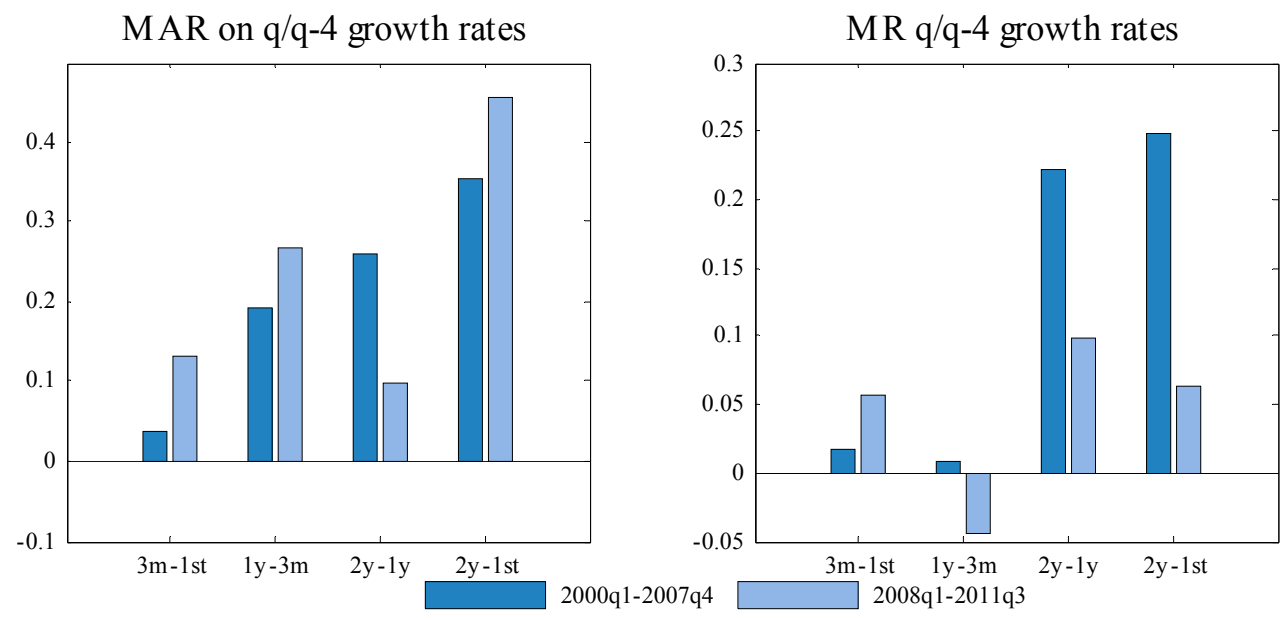

Figure II.10b. Korea: GDP q/q-4 Rates by Vintage of Publication

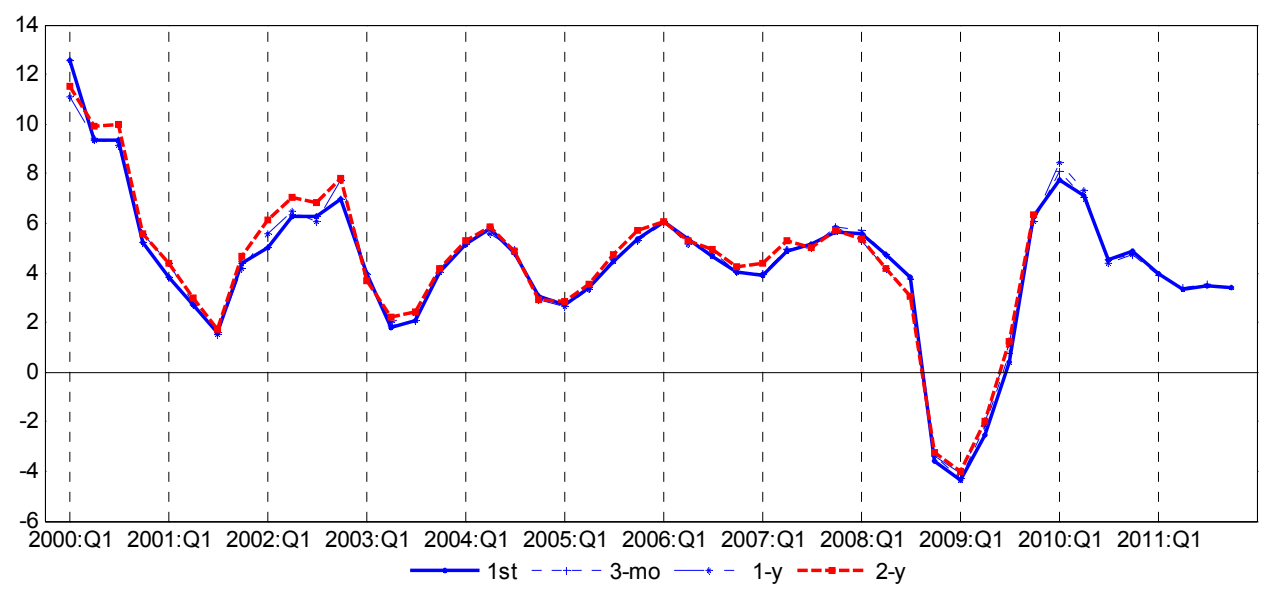

CInternational Monetary Fund. Not for Redistribution 


\section{MeXICO}

Table II.11. Mexico: Statistics on Revisions to GDP Growth Rates (before and after 2008)

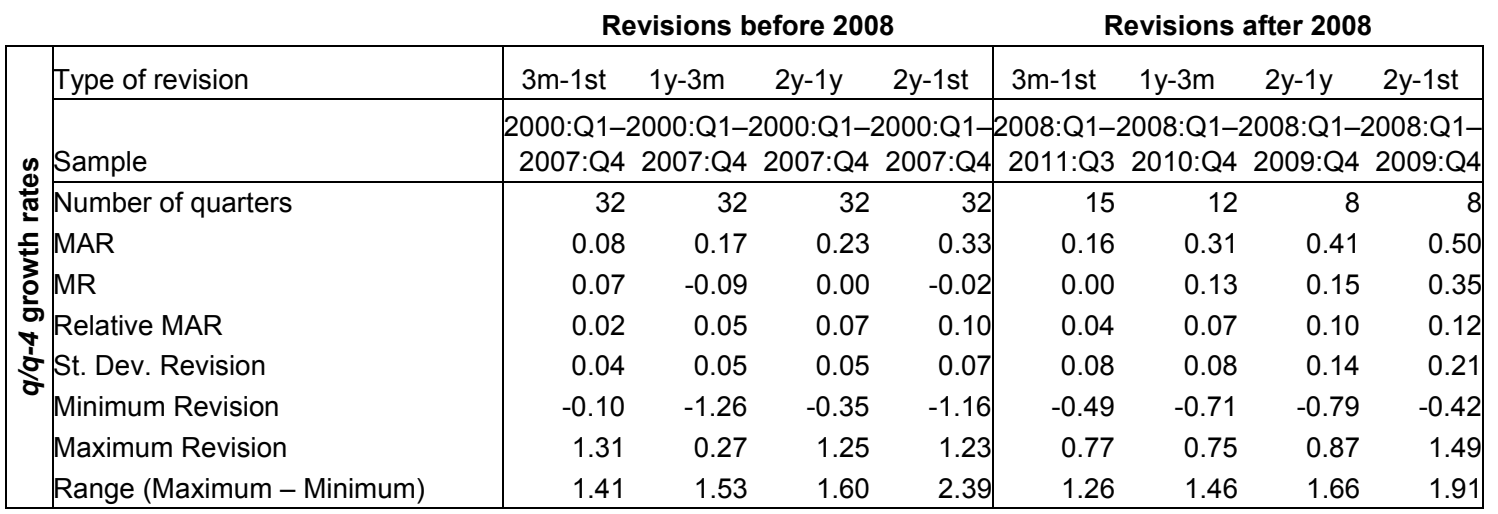

Figure II.11a. Mexico: MAR and MR to GDP q/q-4 Growth Rates (before and after 2008)
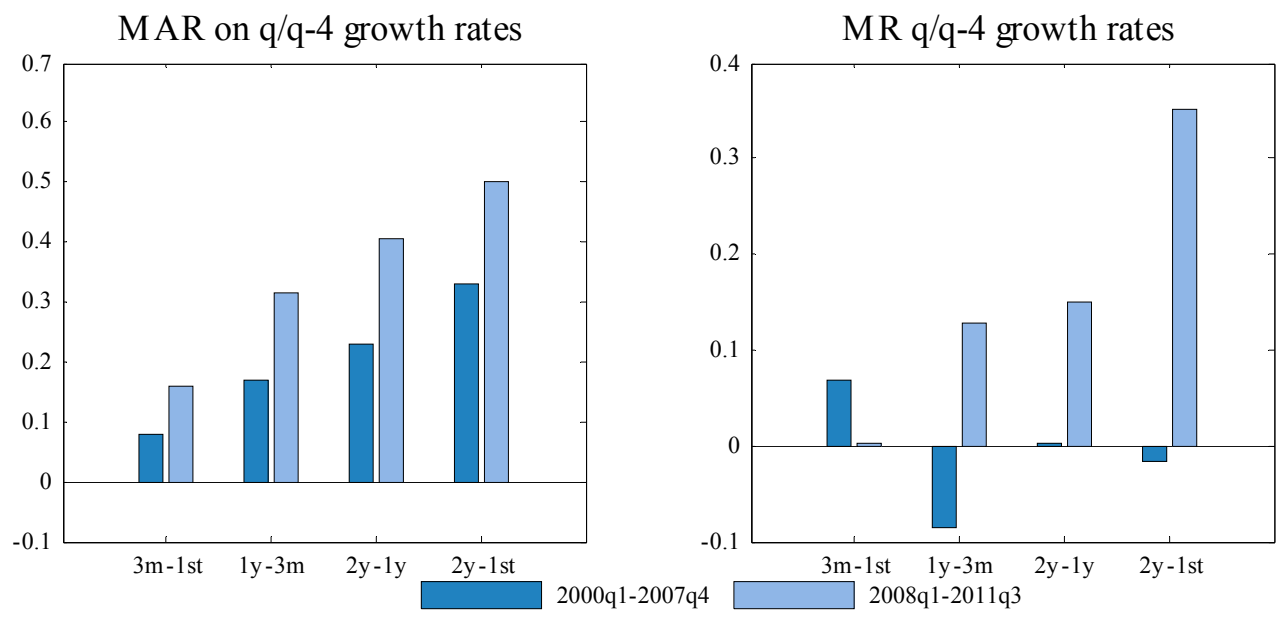

Figure II.11b. Mexico: GDP q/q-4 Rates by Vintage of Publication

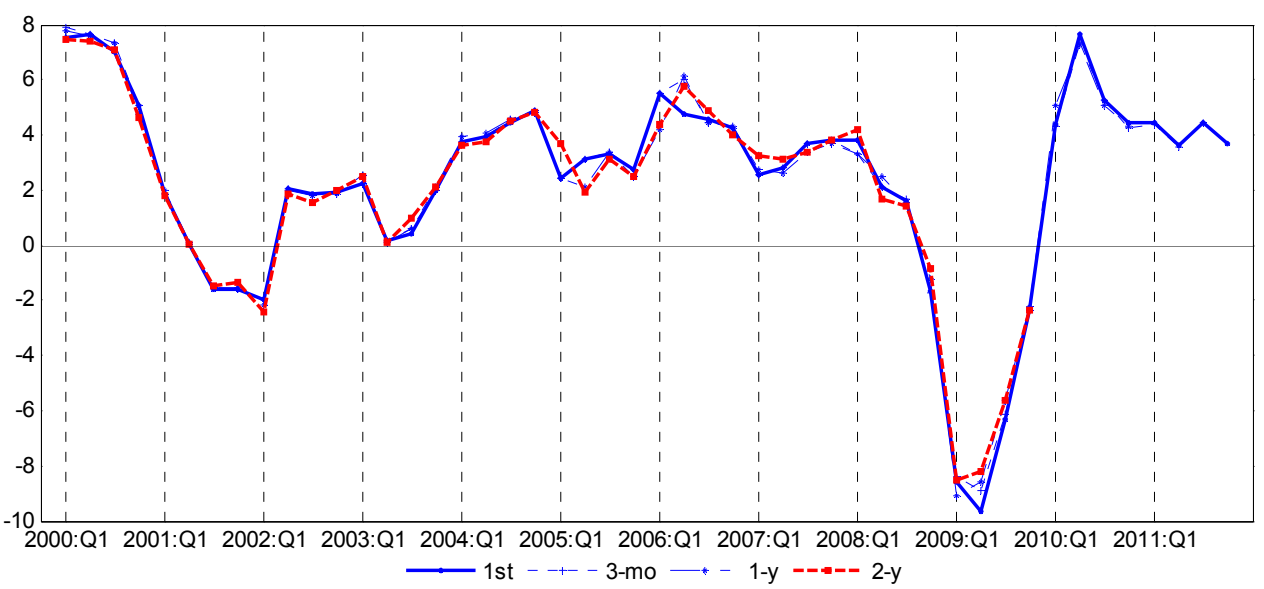

CInternational Monetary Fund. Not for Redistribution 


\section{RUSSIAN FEDERATION}

Table II.12. Russian Federation: Statistics on Revisions to GDP Growth Rates (before and after 2008)

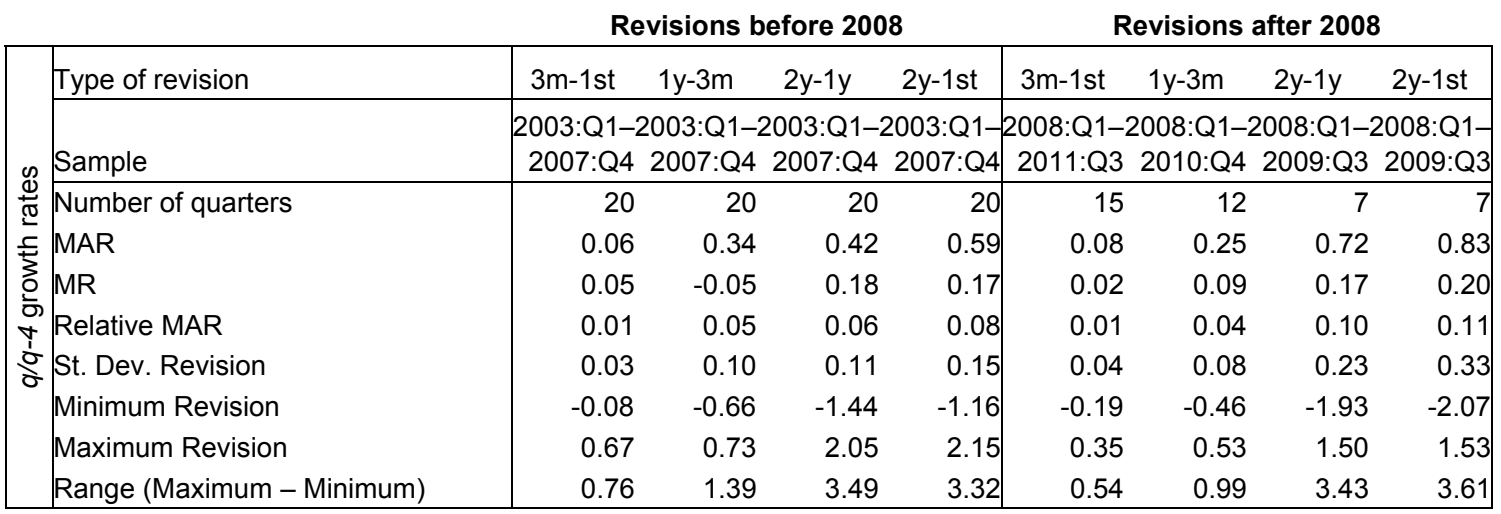

Figure II.12a. Russian Federation: MAR and MR to GDP q/q-4 Growth Rates (before and after 2008)

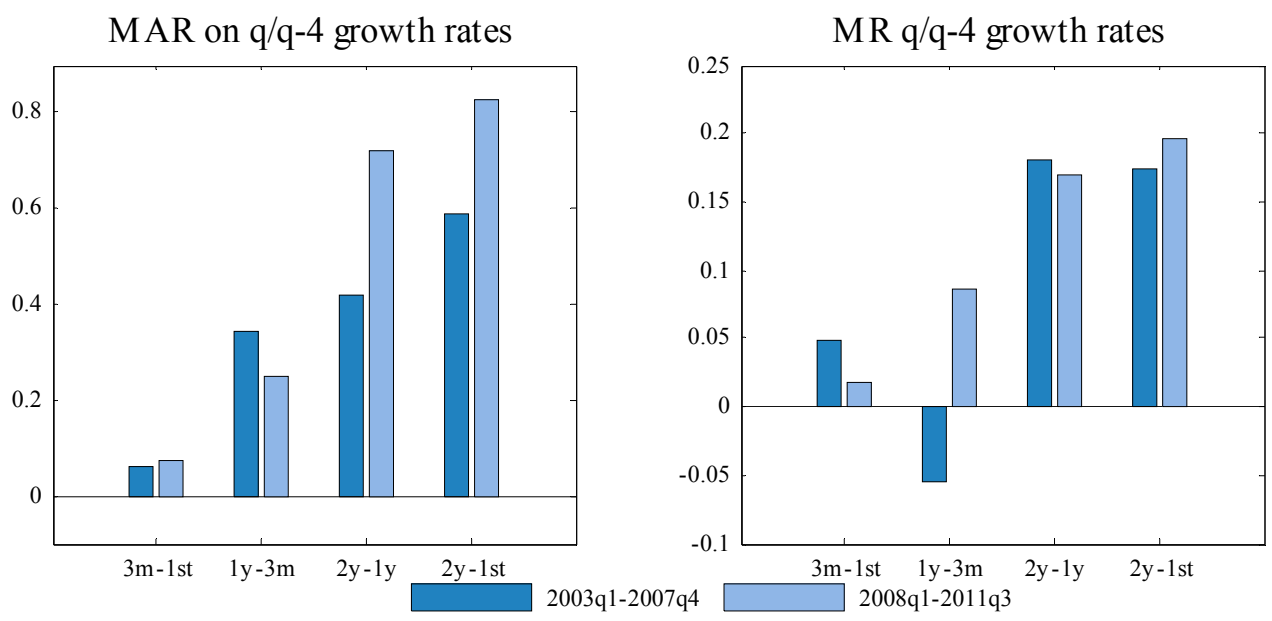

Figure II.12b. Russian Federation: GDP q/q-4 Rates by Vintage of Publication

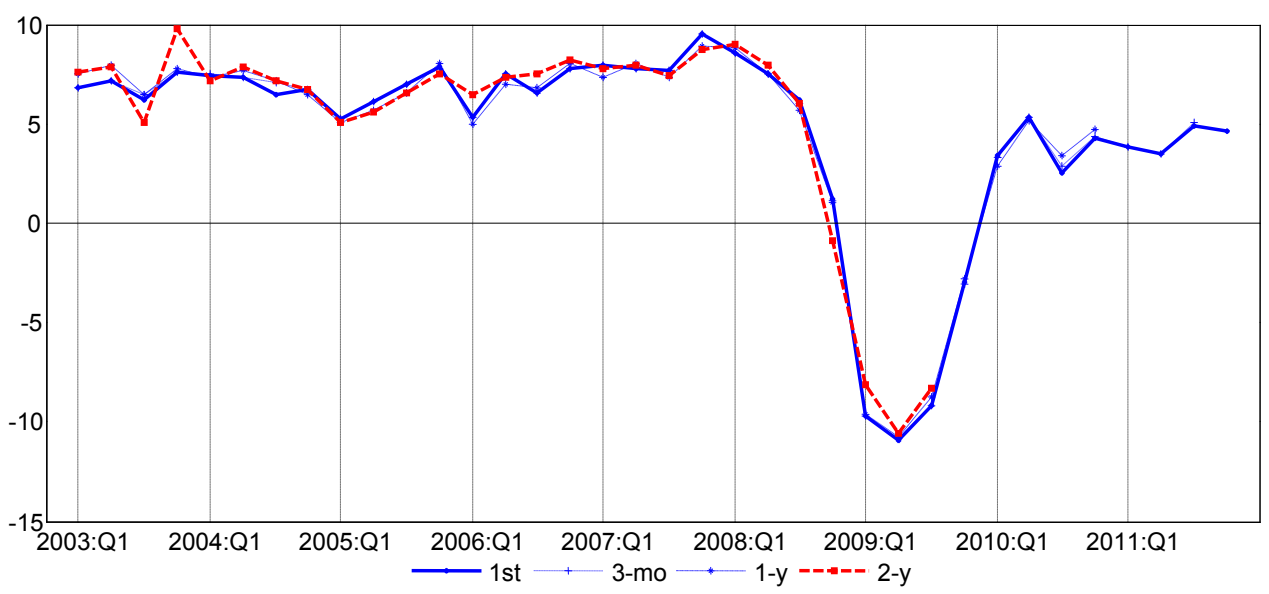

CInternational Monetary Fund. Not for Redistribution 


\section{SOUTH AFriCA}

Table II.13. South Africa: Statistics on Revisions to GDP Growth Rates (before and after 2008)

\begin{tabular}{|c|c|c|c|c|c|c|c|c|c|}
\hline \multirow{2}{*}{\multicolumn{2}{|c|}{ Type of revision }} & \multicolumn{4}{|c|}{ Revisions before 2008} & \multicolumn{4}{|c|}{ Revisions after 2008} \\
\hline & & $3 m-1 s t$ & $1 y-3 m$ & $2 y-1 y$ & $2 y-1 s t$ & $3 m-1 s t$ & $1 y-3 m$ & $2 y-1 y$ & $2 y-1 s t$ \\
\hline \multirow{9}{*}{ 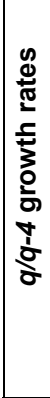 } & Sample & $\begin{array}{r}\text { 2002:Q1- } \\
2007: Q 4\end{array}$ & $\begin{array}{r}2002: Q 1- \\
2007: Q 4\end{array}$ & $\begin{array}{r}2002: Q 1- \\
2007: Q 4 \\
\end{array}$ & $\begin{array}{r}2002: Q 1 \\
2007: Q 4\end{array}$ & $\begin{array}{r}\text { 2008:Q1- } \\
\text { 2011:Q3 }\end{array}$ & $\begin{array}{r}2008: Q 1- \\
2010: Q 4 \\
\end{array}$ & $\begin{array}{l}\text { 2008:Q1-2 } \\
\text { 2009:Q4 }\end{array}$ & $\begin{array}{r}2008: Q 1- \\
2009: Q 4 \\
\end{array}$ \\
\hline & Number of quarters & 24 & 24 & 24 & 24 & 15 & 12 & 8 & 8 \\
\hline & MAR & 0.10 & 0.53 & 0.33 & 0.84 & 0.04 & 0.27 & 0.25 & 0.38 \\
\hline & MR & 0.08 & 0.48 & 0.26 & 0.82 & 0.00 & 0.21 & 0.07 & 0.38 \\
\hline & Relative MAR & 0.03 & 0.13 & 0.07 & 0.19 & 0.02 & 0.10 & 0.10 & 0.15 \\
\hline & St. Dev. Revision & 0.05 & 0.12 & 0.09 & 0.14 & 0.02 & 0.12 & 0.14 & 0.06 \\
\hline & Minimum Revision & -0.10 & -0.17 & -0.31 & -0.26 & -0.22 & -0.12 & -0.53 & 0.05 \\
\hline & Maximum Revision & 1.34 & 1.25 & 1.10 & 1.81 & 0.09 & 0.86 & 0.55 & 0.71 \\
\hline & Range (Maximum - Minimum) & 1.44 & 1.42 & 1.41 & 2.08 & 0.31 & 0.98 & 1.08 & 0.66 \\
\hline
\end{tabular}

Figure II.13a. South Africa: MAR and MR to GDP q/q-4 Growth Rates (before and after 2008)
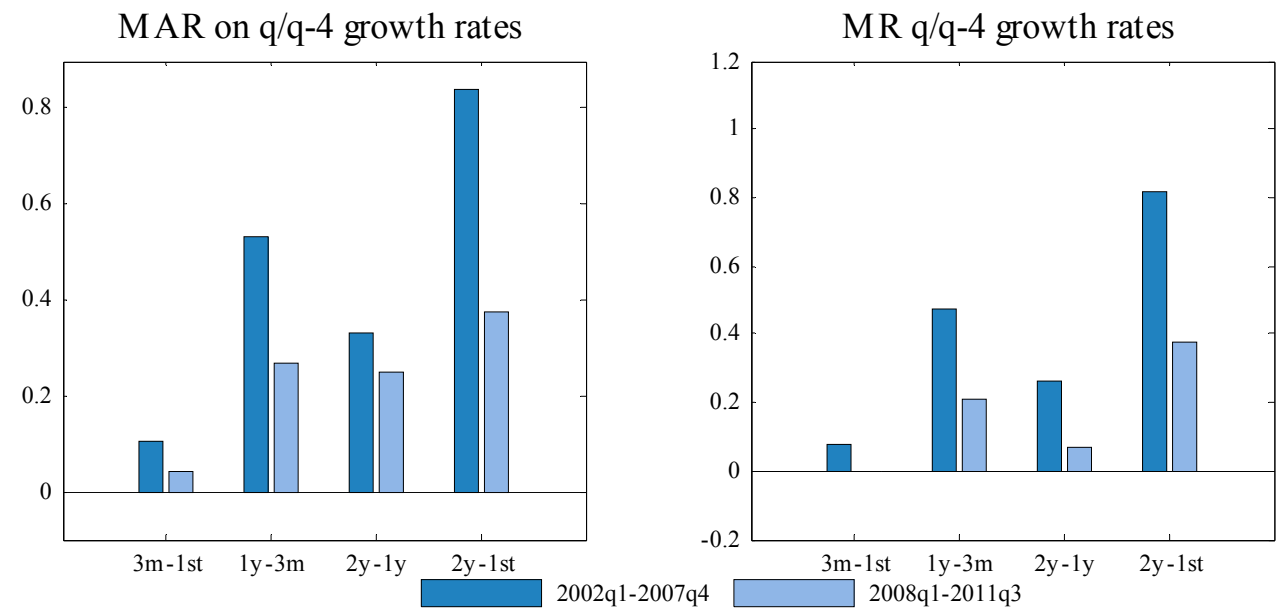

Figure II.13b. South Africa: GDP q/q-4 Rates by Vintage of Publication

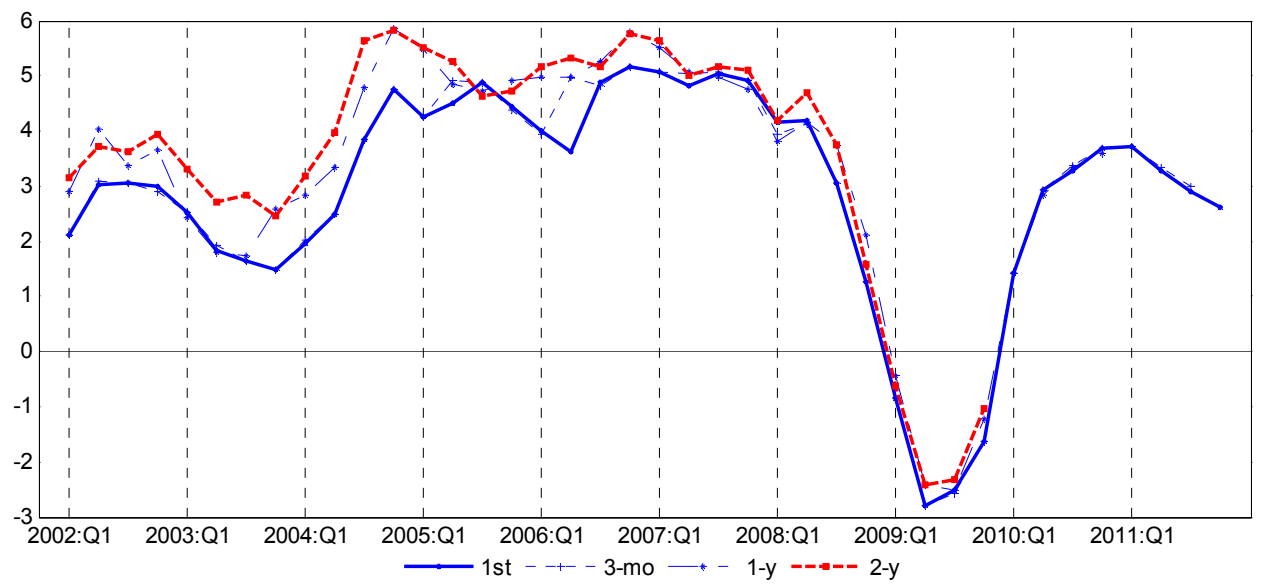

CInternational Monetary Fund. Not for Redistribution 


\section{TURKEY}

Table II.14. Turkey: Statistics on Revisions to GDP Growth Rates (before and after 2008)

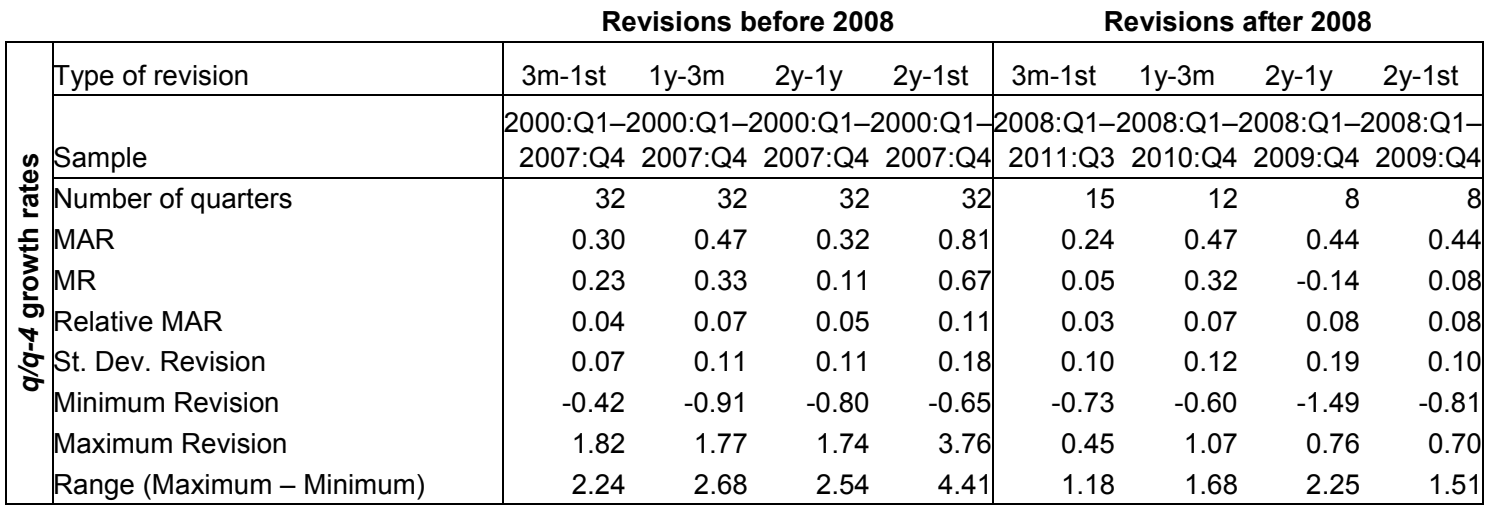

Figure II.14a. Turkey: MAR and MR to GDP q/q-4 Growth Rates (before and after 2008)
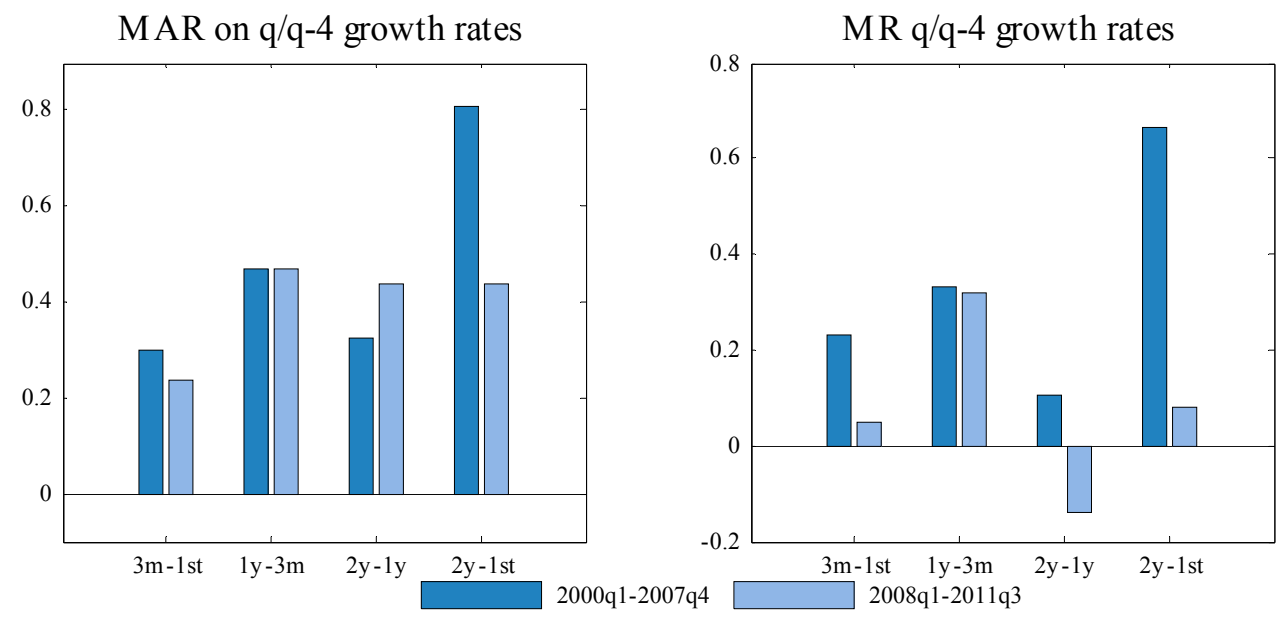

Figure II.14b. Turkey: GDP q/q-4 Rates by Vintage of Publication

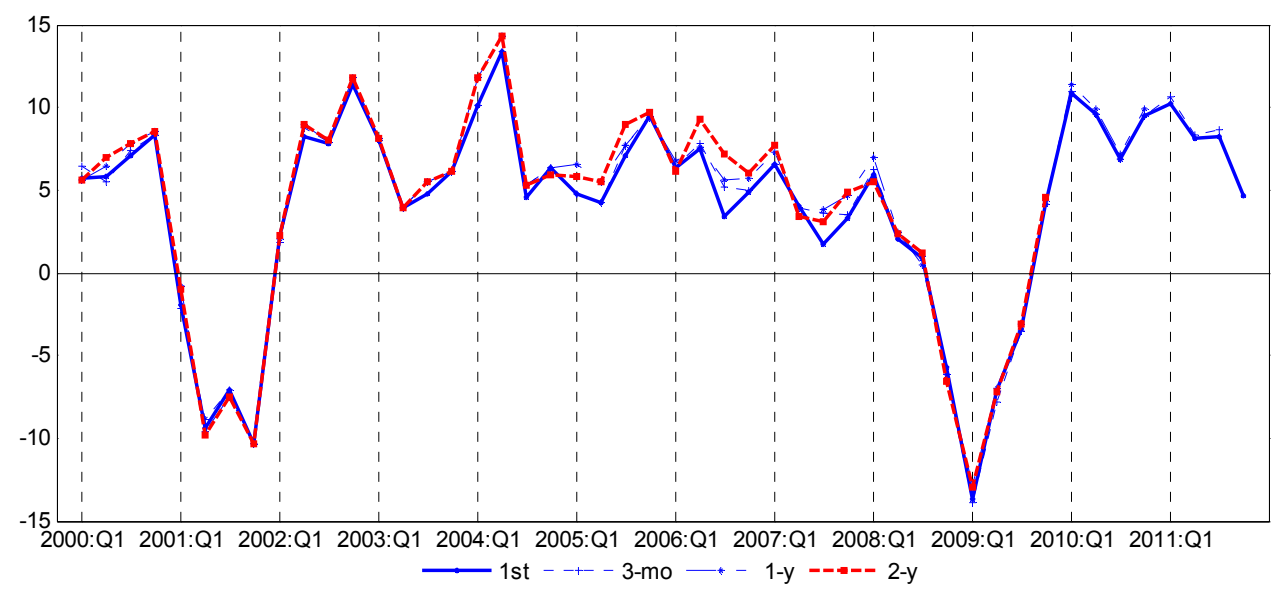

CInternational Monetary Fund. Not for Redistribution 


\section{UNITED KINGDOM}

Table II.15. U.K.: Statistics on Revisions to GDP Growth Rates (before and after 2008)

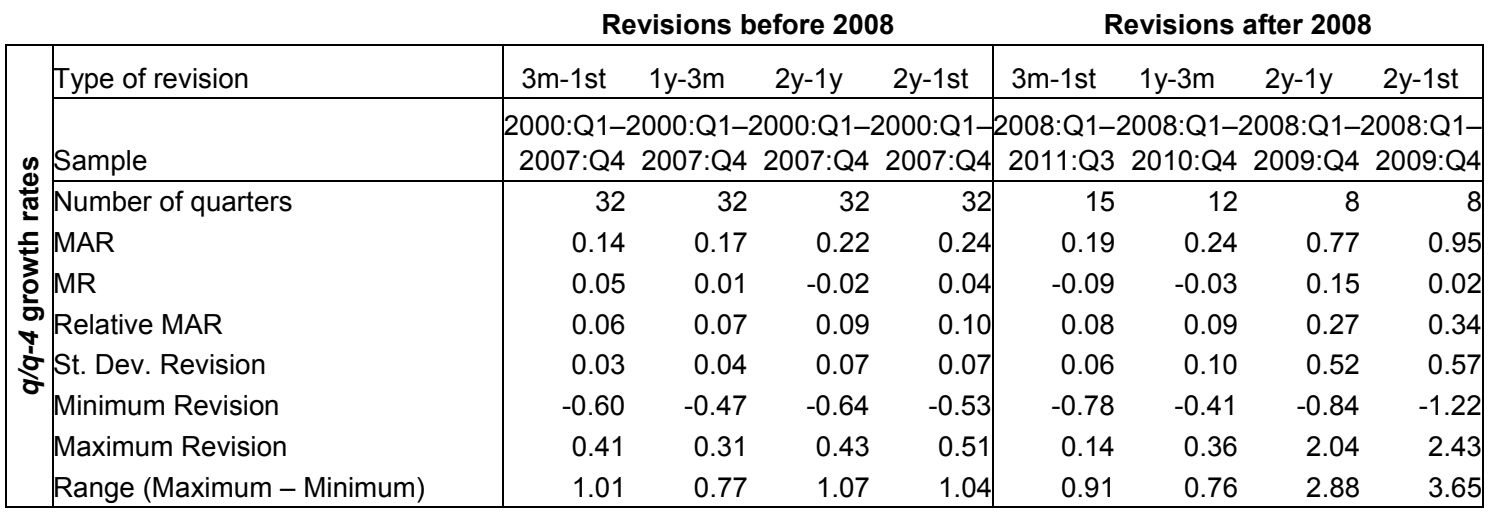

Figure II.15a. U.K.: MAR and MR to GDP q/q-4 Growth Rates (before and after 2008)
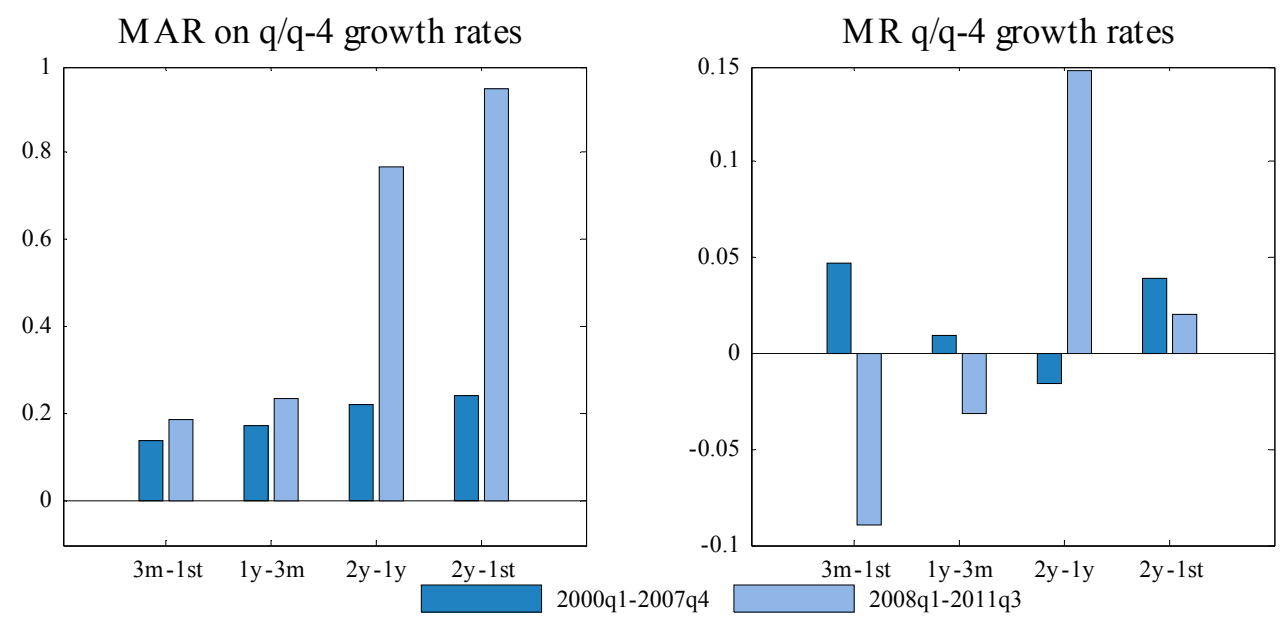

Figure II.15b. U.K.: GDP q/q-4 Rates by Vintage of Publication

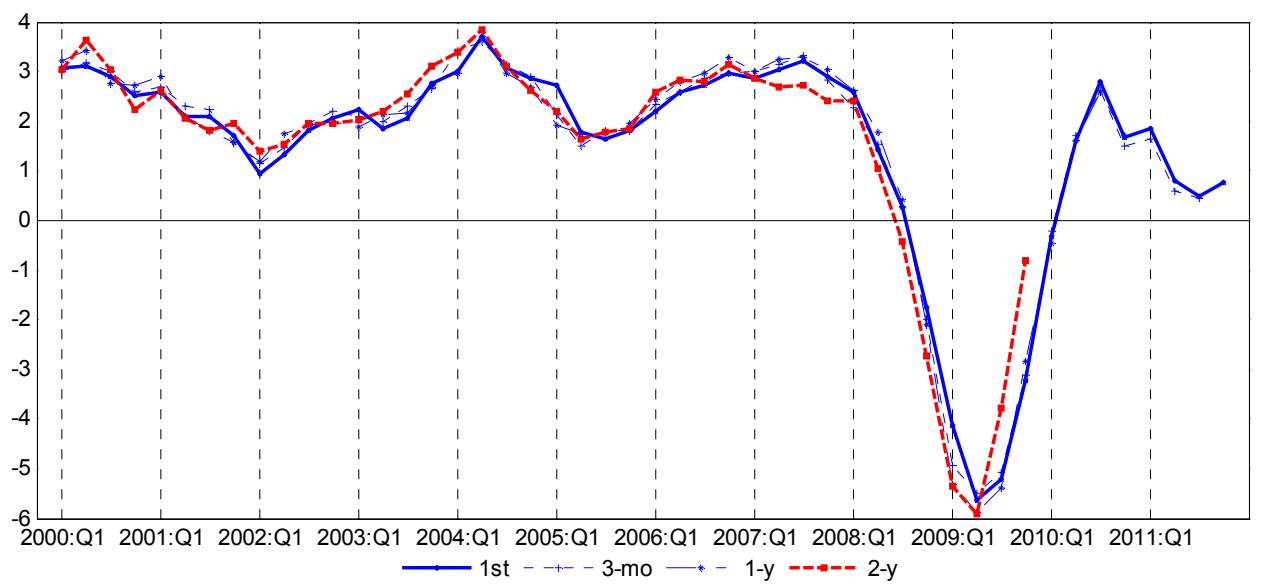

CInternational Monetary Fund. Not for Redistribution 


\section{United States OF AMERICA}

Table II.16. U.S.A.: Statistics on Revisions to GDP Growth Rates (before and after 2008)

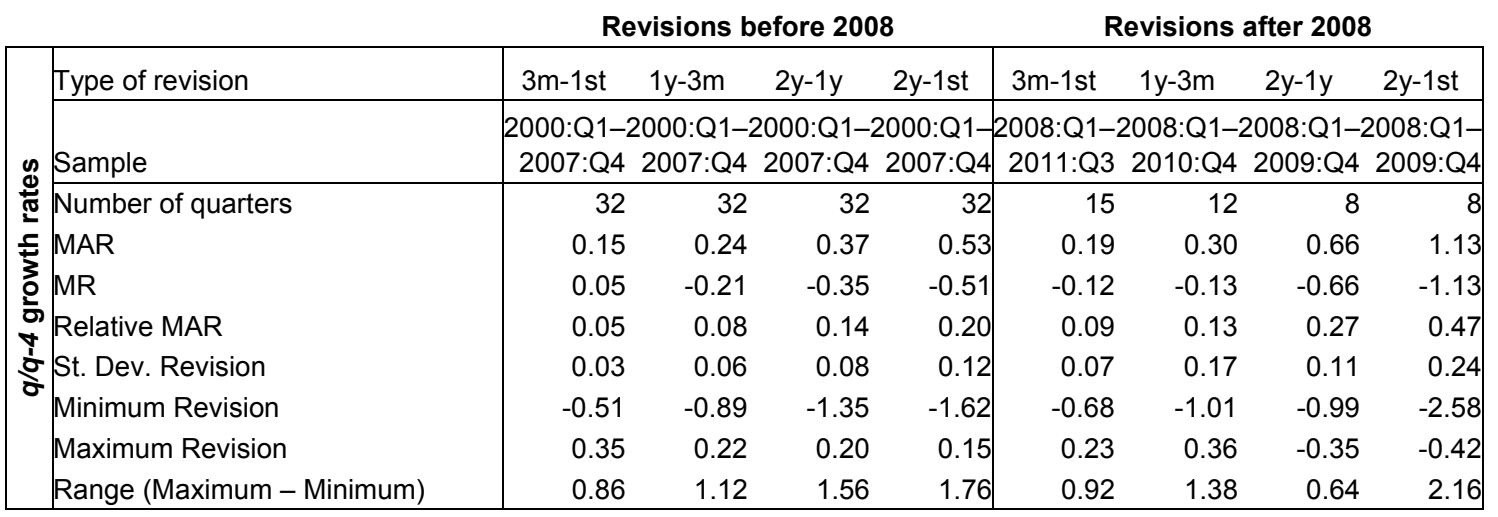

Figure II.16a. U.S.A.: MAR and MR to GDP q/q-4 Growth Rates (before and after 2008)
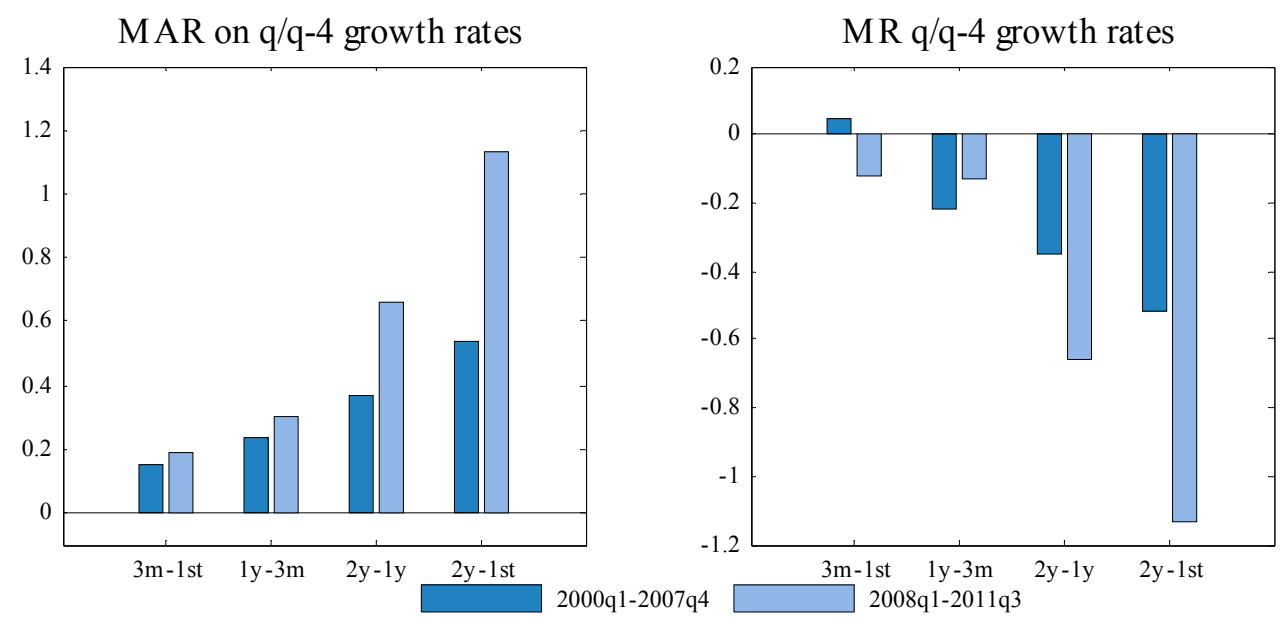

Figure II.16b. U.S.A.: GDP q/q-4 Rates by Vintage of Publication

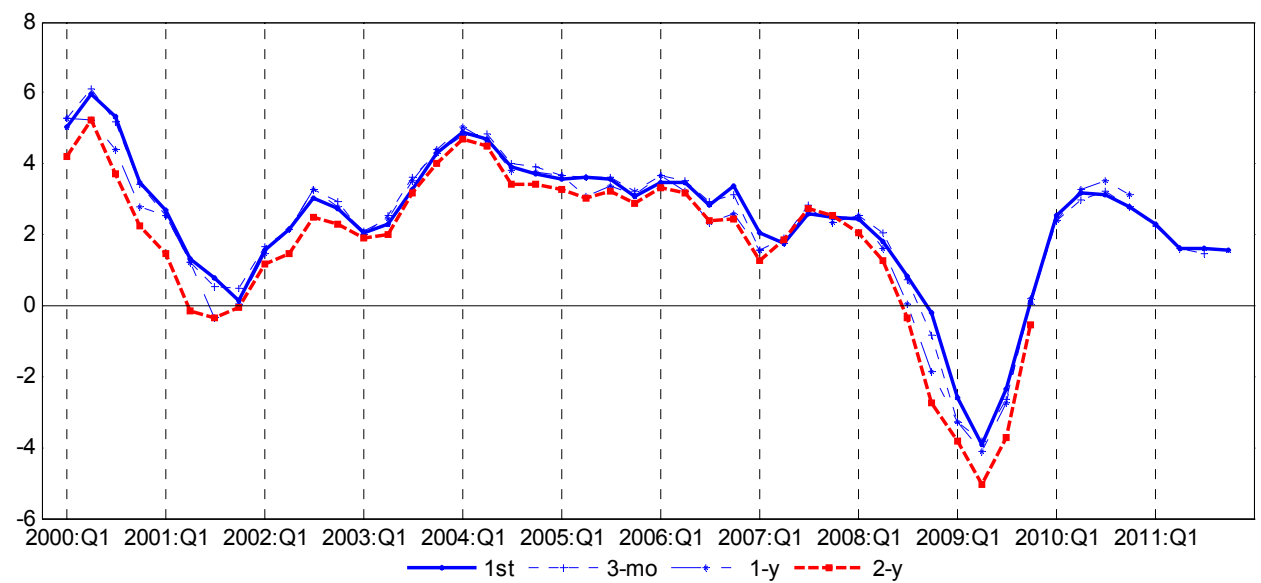

CInternational Monetary Fund. Not for Redistribution 


\section{Appendix III. Statistical Analysis of Revisions}

The statistical analysis of revisions allows to assess how reliable is an early estimate. A revisions analysis aims at quantifying and summarizing the revision process of early estimates compared with estimates published in subsequent periods. In this appendix we provide a formal definition of revision and present some statistics to summarize the revision process, namely a sequence of revisions over time for the same variable. These statistics are commonly found in research papers on revisions by the OECD (see Di Fonzo, 2005 and McKenzie, 2006).

A revision is defined as the difference between a later (more recent) estimate and an earlier estimate (Di Fonzo, 2005). Let $y_{t}^{L}$ and $y_{t}^{E}$ denote respectively the later and earlier estimates of a same variable ${ }^{19} y$ in period $t$. Revision $r_{t}^{L, E}$ is calculated as

$$
r_{t}^{L, E}=y_{t}^{L}-y_{t}^{E} \text {. }
$$

Let us suppose there are revisions observed for $N$ consecutive quarters, denoted with $t=1, \ldots, N$. To understand the characteristics of this revision process, it is convenient to calculate the following summary indicators ${ }^{20}$ :

- $\quad$ Mean Absolute Revision (MAR)

$$
M A R^{L, E}=\frac{1}{N} \sum_{t=1}^{N}\left|r_{t}^{L, E}\right|
$$

The MAR measures the average absolute size of revisions. Considering the absolute value of revisions, this indicator compensates revisions with different sign and provides information on the magnitude of revisions. The minimum value of $M A R$ is zero, attained when there are no revisions $\left(r_{t}^{L, E}=0\right.$ for any $t$ ); revisions different from zero lead to positive $M A R$ values.

- $\quad$ Mean Revision (MR)

$$
M R^{L, E}=\frac{1}{N} \sum_{t=1}^{N} r_{t}^{L, E}
$$

The $M R$ is an indicator of direction of revisions. It provides an indication of systematic patterns in the revision process: when the $M R$ is positive (negative), the earlier estimate underestimates (overestimates) the later estimate. Differently from the $M A R$, the $M R$ can be zero even when revisions are different from zero (when positive and negative revisions

\footnotetext{
${ }^{19}$ The variable can be expressed in level or in a transformation of it, for instance rates of change.

${ }^{20}$ All these indicators are available in the spreadsheet templates for revisions analysis available from the OECD's Real-Time Data and Revisions Database website.
} 
perfectly compensate each other). Values of $M R$ that are significantly far from zero indicate a systematic difference between the earlier estimate and the later estimate.

- $\quad$ Relative MAR (RMAR)

$$
R M A R^{L, E}=\frac{\frac{1}{N} \sum_{t=1}^{N}\left|r_{t}^{L, E}\right|}{\frac{1}{N} \sum_{t=1}^{N}\left|y_{t}^{L}\right|}=\frac{M A R^{L, E}}{\frac{1}{N} \sum_{t=1}^{N}\left|y_{t}^{L}\right|}
$$

The $R M A R$ is useful to compare the relative size of revisions across variables having different magnitude, as it adjusts the $M A R$ value for the mean absolute size of the variable in the period.

- $\quad$ Standard Deviation of Revisions $(S D R)^{21}$

$$
S D R^{L, E}=\sqrt{\frac{1}{N(N-1)}\left[\sum_{t=1}^{N}\left(r_{t}^{L, E}\right)^{2}+\frac{4}{3} \sum_{t=2}^{N} r_{t}^{L, E} r_{t-1}^{L, E}+\frac{2}{3} \sum_{t=3}^{N} r_{t}^{L, E} r_{t-2}^{L, E}\right]}
$$

The $S D R$ provides a measure of variability of revisions around their average value (namely the $M R$ value). Its value is small when revisions are concentrated around the mean revision.

- $\quad$ Minimum Revision

$$
\operatorname{MinR}^{L, E}=\min _{t} r_{t}^{L, R}
$$

which is the minimum revision observed in the period $t=1, \ldots, N$.

\section{- $\quad$ Maximum Revision}

$$
\operatorname{Max}^{L, E}=\max _{t} r_{t}^{L, R},
$$

which is the maximum revision observed in the period $t=1, \ldots, N$.

- Range

$$
\operatorname{Rang}^{L, E}=\operatorname{MaxR}^{L, E}-\operatorname{MinR}^{L, E}
$$

The range is the maximum interval that contains all the observed revisions. It is a measure of variability, but it is less robust than the $S D R$ because it is affected by the presence of abnormal revisions in the period.

\footnotetext{
${ }^{21}$ As suggested in Di Fonzo (2005), we use the variance estimator proposed by Newey and West (1987) which adjusts for the presence of both eteroskedasticity and autocorrelation of unknown form in the revisions. The Newey-West estimator is the one calculated in the spreadsheets available from the OECD MEI website.
} 